\title{
Multiple small RNA pathways regulate the silencing of repeated and foreign genes in C. elegans
}

\author{
Sylvia E.J. Fischer, ${ }^{1,2}$ Qi Pan, ${ }^{1,2,3}$ Peter C. Breen, ${ }^{1,2}$ Yan Qi, ${ }^{1,2,4}$ Zhen Shi, ${ }^{1,2}$ Chi Zhang, ${ }^{1,2,5}$ \\ and Gary Ruvkun ${ }^{1,2,6}$ \\ ${ }^{1}$ Department of Molecular Biology, Massachusetts General Hospital, Boston, Massachusetts 02114, USA; ${ }^{2}$ Department of \\ Genetics, Harvard Medical School, Boston, Massachusetts 02114, USA
}

Gene segments from other organisms, such as viruses, are detected as foreign and targeted for silencing by RNAi pathways. A deep-sequencing map of the small RNA response to repeated transgenes introduced to Caenorhabditis elegans revealed that specific segments are targeted by siRNAs. Silencing of the foreign gene segments depends on an antiviral response that involves changes in active and silent chromatin modifications and altered levels of antisense siRNAs. Distinct Argonaute proteins target foreign genes for silencing or protection against silencing. We used a repeated transgene in a genome-wide screen to identify gene disruptions that enhance silencing of foreign genetic elements and identified 69 genes. These genes cluster in four groups based on overlapping sets of coexpressed genes, including a group of germline-expressed genes that are likely coregulated by the E2F transcription factor. Many of the gene inactivations enhance exogenous RNAi. About half of the 69 genes have roles in endogenous RNAi pathways that regulate diverse processes, including silencing of duplicated genes and transposons and chromosome segregation. Of these newly identified genes, several are required for siRNA biogenesis or stability in the oocyte-specific ERGO-1 pathway, including eri-12, encoding an interactor of the RNAi-defective protein RDE-10, and ntl-9/CNOT9, one of several CCR4/NOT complex genes that we identified. The conserved ARF-like small GTPase ARL-8 is required specifically for primary siRNA biogenesis or stability in the sperm-specific ALG-3/4 endogenous RNAi pathway.

[Keywords: RNA silencing; transgene; siRNA; RNAi; C. elegans.]

Supplemental material is available for this article.

Received August 15, 2012; revised version accepted November 19, 2013.

Small RNAs (18-32 nucleotides [nt]) regulate gene expression, chromosome segregation, DNA elimination, and viral defense through post-transcriptional and transcriptional mechanisms. Exogenous RNAi, the RNAi response to administered dsRNA or siRNAs, is a viral defense pathway; protein factors mediating exogenous RNAi are also required for the silencing of viruses (Lu et al. 2005; Schott et al. 2005; Wilkins et al. 2005; Félix et al. 2011). Factors required for Caenorhabditis elegans exogenous RNAi include many conserved proteins, such as the endoribonuclease Dicer (DCR-1) (Grishok et al. 2001; Ketting et al. 2001), the Argonaute protein RDE-1 (Tabara et al. 1999), and a dsRNA-binding protein, RDE-4 (Tabara et al. 2002), as well as several effector Argonaute proteins. In addition, C. elegans uses proteins shared with

Present addresses: ${ }^{3}$ Boehringer Ingelheim, Danbury, CT 06877, USA; ${ }^{4}$ Amherst College, Amherst, MA 01002, USA; ${ }^{5}$ Warp Drive Bio, Cambridge, MA 02139, USA.

${ }^{6}$ Corresponding author

E-mail ruvkun@molbio.mgh.harvard.edu

Article is online at http://www.genesdev.org/cgi/doi/10.1101/gad.233254.113. plants and fungi but few other animal species for the amplification of the RNAi response-most importantly, RNA-dependent RNA polymerases (RdRPs) that amplify secondary siRNAs (Sijen et al. 2001). Exogenous RNAi triggers not only destruction of the targeted mRNA in the cytoplasm but cotranscriptional silencing of the same target genes, mediated by the NRDE proteins (including an Argonaute protein, NRDE-3, which shuttles siRNAs from the cytoplasm into the nucleus), to inhibit RNA polymerase II elongation and induce deposition of $\mathrm{H} 3 \mathrm{~K} 9 \mathrm{me} 3$ chromatin marks on the genetic locus targeted by complementary siRNAs (Guang et al. 2008, 2010; Burkhart et al. 2011; Gu et al. 2012).

The complex machinery of RNAi has regulatory roles apart from immunity against newly introduced foreign

(C) 2013 Fischer et al. This article is distributed exclusively by Cold Spring Harbor Laboratory Press for the first six months after the full-issue publication date (see http://genesdev.cshlp.org/site/misc/terms.xhtml). After six months, it is available under a Creative Commons License (Attribution-NonCommercial 3.0 Unported), as described at http:// creativecommons.org/licenses/by-nc/3.0/. 
genetic elements. Endogenous RNAi pathways that silence a range of genes resident in genomes have also been identified in yeast, plants, nematodes, fruit flies, and mice. C. elegans endogenous RNAi pathways can be distinguished by the distinct Argonaute proteins and the length and $5^{\prime}$ nucleotides of the siRNAs as well as the gene loci from which the small RNAs are derived. In oocytes and embryos, the ERGO-1-associating 26G siRNAs and NRDE-3-associating 22G siRNAs silence recently duplicated genes (Vasale et al. 2010; Fischer et al. 2011); the ALG-3 and ALG-4 26G siRNA pathway in sperm is required for sperm morphogenesis (Conine et al. 2010). CSR-1-associated 22G siRNAs direct chromatin modifications on germline-expressed genes (Claycomb et al. 2009). Many 22G siRNAs associate with C. elegansspecific Argonautes (the so-called WAGOs); these siRNAs are produced from many genes, including transposons, and direct the silencing of transposons (Gu et al. 2009). Several of the endogenous RNAi pathways act in the nucleus. The ERGO-1 endogenous RNAi pathway acts upstream of the NRDE-3 Argonaute that shuttles endogenous siRNAs into the nucleus. NRDE-3 in conjunction with other NRDE proteins directs cotranscriptional silencing of siRNA target genes and directs deposition of the inheritable silent chromatin mark histone H3K9me3. The CSR-1 endogenous RNAi pathway is required for chromosome segregation (Claycomb et al. 2009) and is also thought to confer protection against silencing (Lee et al. 2012).

Small RNA pathways compete for limiting factors that are required in multiple pathways (Ambros et al. 2003; Lund et al. 2011). A few genes that function as negative regulators of the C. elegans exogenous RNAi pathway have emerged from noncomprehensive genetic screens for enhanced response to exogenous RNAi, revealing the ERI-1 nuclease (Kennedy et al. 2004), the ERI-2/RRF-3 RdRP (Simmer et al. 2002), ERI-3 (Duchaine et al. 2006), an activating mutation in DCR-1, the Dicer ortholog (Pavelec et al. 2009), the ERI-5 Tudor protein (Duchaine et al. 2006), the ERI-6/7 helicase (Fischer et al. 2008), ERI-9 (Pavelec et al. 2009), and the Argonaute ERI-8/ERGO-1 (Pavelec et al. 2009; Fischer et al. 2011). The activity of these genes normally attenuates the response to ingested or injected dsRNA but is also required for certain endogenous RNAi pathways. The concomitant increase in exogenous RNAi response and decrease in endogenous RNAi response may be due to competition for particular limiting factors that are shared between multiple distinct small RNA pathways; for example, an Argonaute protein (Yigit et al. 2006). Alternatively, factors repressed by the endogenous RNAi pathway could encode limiting components of the exogenous RNAi pathway.

The closest homologs of many endogenous RNAi pathway factors identified in C. elegans fulfill similar functions in higher organisms; e.g., the endogenous siRNA biogenesis machinery in the ERGO-1 pathway resembles piRNA biogenesis complexes identified in flies and mammals, the ERI-6/7 helicase (Fischer et al. 2011) may be functionally equivalent to its putative orthologs Drosophila Armitage (Saito et al. 2010) and mouse Mov10L1 (Zheng et al. 2010), and the Piwi-like Argonaute ERGO-1 could act like Drosophila Piwi and mouse MILI and MIWI2. The endogenous siRNAs produced by the ERI-6/7 helicase and the ERGO-1 Argonaute resemble piRNAs in terms of 2'-O-methylation of the $3^{\prime}$-terminal nucleotide, and their potential to trigger siRNA biogenesis in trans is similar to piRNAs (Bagijn et al. 2012; Montgomery et al. 2012).

Transgene silencing is mediated by many of the same factors as those needed for RNAi (Tabara et al. 1999; Ketting and Plasterk 2000; Vastenhouw et al. 2003; Grishok et al. 2005; Robert et al. 2005), and transgene silencing is enhanced in mutants that display enhanced exogenous RNAi responses (Simmer et al. 2002), arguing that the foreign and repeated genetic elements on transgenes are silenced by RNAi. Highly repetitive transgenes also accumulate heterochromatic marks concomitantly with silencing by RNAi pathways (She et al. 2009; Towbin et al. 2010; Arico et al. 2011), suggesting that they are subject to transcriptional gene silencing in addition to mRNA degradation. Thus, the silencing or desilencing of transgenes is an excellent surrogate assay for defects in small RNA-mediated silencing. In addition, because transgenes bear many of the foreign marks that are also associated with viruses, the RNAi response to transgenes may actually be closer to the biology of RNAi as an antiviral defense than the rather artificial feeding or injection of dsRNA that is used for exogenous RNAi in the laboratory. The continued silencing of transgenes long after the initial exposure to foreign DNA in transgenesis points to a capacity to mark these genes as foreign and regenerate those marks.

Here we describe a comprehensive analysis of the silencing of a chromosomally integrated, multicopy transgene. The silencing response to this transgene in wild type is similar to antiviral responses: It is mediated by antisense siRNAs and antiviral proteins but also involves changes in active and silencing chromatin marks and multiple Argonaute proteins exerting opposite silencing effects. In a whole-genome RNAi screen for gene inactivations that cause increased silencing of a chromosomally integrated, multicopy transgene, we identified dozens of gene inactivations that cause increased transgene silencing. Analysis of transcriptional coexpression shows that these genes cluster into four groups that appear to be coregulated. Our secondary screens for defects in exogenous RNAi show that many of the genes identified are negative regulators of the antiviral exogenous RNAi pathway. Thus, inactivation of these genes, many of which are conserved in humans, could promote immunity against viruses. Our secondary screens for defects in endogenous RNAi revealed that many of the genes identified mediate multiple gene silencing pathways. These gene inactivations may identify competing pathways that, when inactivated, increase the capacity of the exogenous RNAi pathway to detect transgenes. As examples of genes acting in endogenous RNAi, we describe three new genes acting in the oocyte-specific ERGO-1 endogenous RNAi path- 
way. We also demonstrate a role for the conserved GTPbinding protein ARL-8 in the biogenesis of primary siRNAs in the sperm-specific ALG-3/4 endogenous RNAi pathway.

\section{Results}

A C. elegans siRNA immune response to foreign genes

Foreign genetic segments can be introduced into C. elegans as single-copy integrants or as tandemly repeated transgenes that are either integrated into a chromosome or maintained as a separate unstable minichromosome. Tandemly repeated transgenes, whether integrated chromosomally or as minichromosomes, are silenced in the germline but not in the somatic cells of wild type, whereas single-copy transgenes are not as routinely silenced in the germline. Tandemly repeated transgenes become silenced in somatic cells as well as germline cells in most mutants that cause enhanced exogenous RNAi (eri mutants) (Simmer et al. 2002; Kennedy et al. 2004; Fischer et al. 2008) and can become desilenced in particular RNAi-defective mutants; for example, mut-16 or mut-7 (Simmer et al. 2002). How RNAi pathways and silencing of repetitive transgenes intersect mechanistically is unknown. We analyzed the C. elegans response to two multicopy (>100 copies) transgenes: One transgene, mgIs 30 , contains three genetic elements from foreign as well as C. elegans sources integrated as a multicopy tandem array into a C. elegans chromosome-the foreign Aequorea victoria gfp and Escherichia coli lacZ genes and an endogenous collagen gene (rol-6) (Fig. 1A). These genes are expressed in several somatic tissues of wild type: the hypodermis, neurons, and the somatic tissues of the gonad. A second multicopy integrated transgene that was tested consists of gfp under the control of a ubiquitous sur-5 promoter.

The genetic markers or GFP from these transgenes are expressed in the somatic cells of wild type but are strongly silenced in the somatic cells of eri-6/7/helicase or ergo-1/Argonaute-enhanced RNAi mutants. For example, wild type carrying $m g I s 30$ shows a rolling phenotype conferred by the dominant mutation in rol-6(su1006). However, loss of eri-6/7/helicase or the ergo-1/Argonaute causes complete silencing of the mutant rol-6 collagen expression from the transgene; the mRNA encoding the mutant collagen is not transcribed or translated, and no rolling phenotype is observed (Table 1).

Deep sequencing of the small RNA repertoire produced from the genome of a multicopy $m g I s 30$ transgenic strain revealed that siRNAs are generated targeting distinct segments of the transgene: the promoter, the ORF, the $3^{\prime}$ untranslated region (UTR), and downstream vector sequences (Fig. 1B). These siRNAs harbor the hallmarks of secondary siRNAs produced by RdRPs in response to a primary trigger siRNA or piRNA; these are $22 \mathrm{nt}$ in length, and the $5^{\prime}$ nucleotide is a guanine (Supplemental Fig. 1A).

Paradoxically, even though the rol-6 genetic element is far more potently silenced in an eri-6/7 or ergo-1 mutant
(Table 1), deep sequencing of three silenced transgenes (rol-6::1in-14, col-10::1acZ::1in-14, and sur-5::gfp) in the eri-6/7 mutant (Supplemental Fig. 1B,C) showed a 10-fold reduction in antisense transgene siRNAs targeting promoter, coding, and 3' UTR sequences, including rol-6 (Fig. 1C; Supplemental Fig. 1B), an observation confirmed by quantitative RT-PCR (qRT-PCR) (Fig. 1D). As described in more detail below, our analysis favors a shift in the balance between the loading of transgene siRNAs onto a silencing Argonaute versus an anti-silencing Argonaute upon loss of ERI-6/7, accompanied by a histone methylation-based silencing that is not associated with production of siRNAs in the maintenance of the silenced state. Sense siRNAs, present at much lower levels than antisense siRNAs, are not reduced in the ergo- 1 or eri-6/7 mutants (Supplemental Fig. 1D). siRNAs corresponding to lim- $6:: g f p$, a transgene expressed mainly in neurons that is not silenced in eri-6/7 mutants, are not reduced in eri-6/7 mutants.

Foreign genes trigger an antiviral silencing response involving opposing Argonaute proteins and changes in chromatin modifications

To understand the biogenesis and activity of siRNAs that target the foreign and C. elegans gene segments on the transgene, we assayed known RNAi factors for their requirement for transgene silencing in eri-6/7 mutants and, conversely, transgene expression in a wild-type background. The ERGO-1/Argonaute acts in the same endogenous RNAi pathway as the ERI-6/7/helicase. Loss of ergo-1 or eri-6/7 silences the transgene, as measured by the expression of the rol-6 genetic marker (the rolling phenotype). The exogenous RNAi factor DRH-1/helicase is required for transgene silencing in the eri-6/7 mutant (Table 1), indicating that a transgene dsRNA intermediate may be a substrate of the exogenous RNAi machinery DCR-1/Dicer, RDE-4/dsRBD, DRH-1/helicase, and RDE-1/ Argonaute. These factors are also required for silencing of RNA viruses, suggesting that genetic screens for mutations that disrupt the silencing of high-copy somatic transgenes reveal antiviral defense pathways.

Of the siRNAs targeting the rol-6 collagen::lin-14 3' UTR fusion transgene, most target the lin-143' UTR. The lin-14 3' UTR is targeted by the microRNAs (miRNAs) lin-4 (seven sites) and several let-7 family members. We tested and rejected the tantalizing possibility that the abundance of siRNAs targeting the lin-14 $3^{\prime}$ UTR is triggered by miRNAs. First, no lin-14 siRNAs are present in wild-type worms, where the lin-4 miRNA targets the lin-14 3' UTR at late larval and adult stages. Second, when we aligned all siRNAs to the lin-14 3' UTR sequence in the mgIs30 transgenic strain, we found that siRNAs map over the entire 3' UTR except 3' of the poly(A) signal (Supplemental Fig. 1E), although of the six most abundant 7 in-14 siRNAs, five overlap or are adjacent to sequences targeted by the miRNA lin-4, let-7, or mir241. Third, the microRNA lin- 4 and the miRNA-binding Argonaute ALG-1 are not required for transgene silencing in the eri-6/7 mutant (Table 1). In fact, loss of the 
A

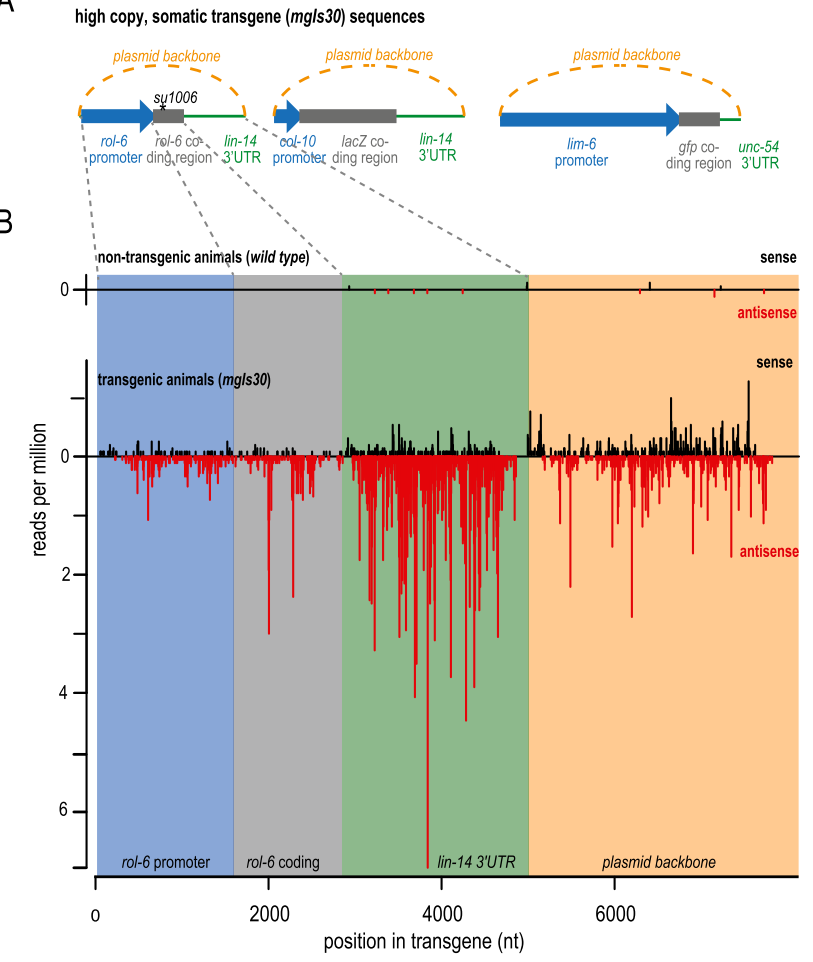

C

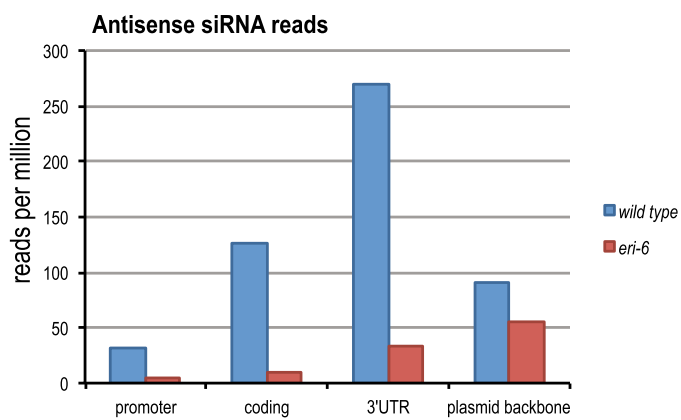

D

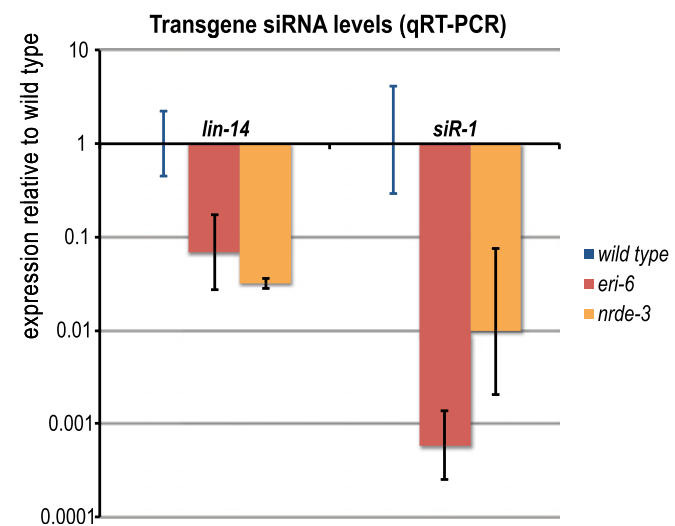

$E$

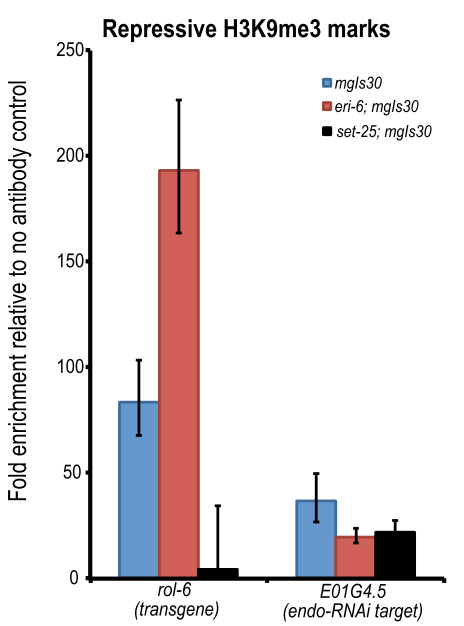

$\mathrm{F}$

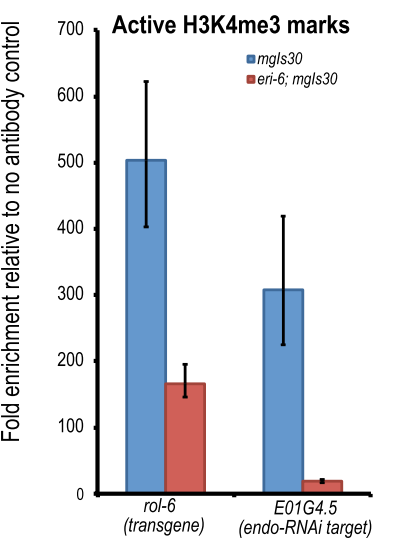

G
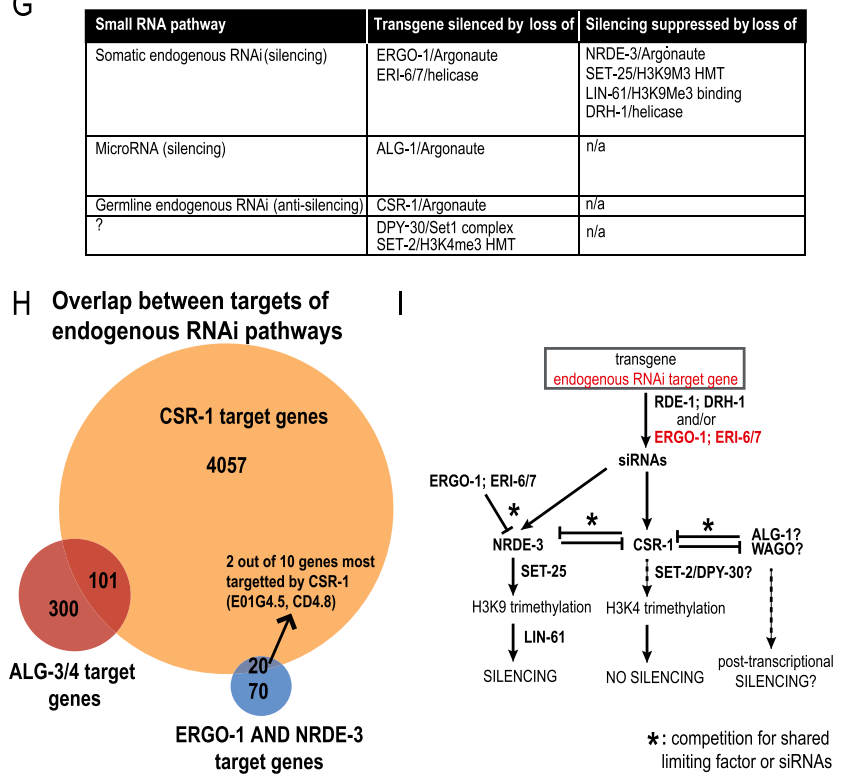

Figure 1. Silencing of multicopy transgenes involves small RNAs, multiple small RNA pathways, and changes in H3K9 and H3K4 trimethylation. (A) Three plasmids constitute the high-copy $m g I s 30$ transgene. (B) The $m g I s 30$ transgene produces sense (black) and antisense (red) siRNAs, as analyzed by small RNA deep sequencing. Indicated are the small RNAs reads in transgenic C. elegans and wild-type C. elegans, corresponding to the rol-6 plasmid that is part of the mgIs30 transgene. $(C)$ Transgene siRNAs are reduced in eri-6/ 7/helicase mutants. (D) lin-14 3' UTR siRNAs are dependent on eri-6/7helicase and nrde-3/Argonaute. siR-1 is an eri-6/7-dependent endogenous siRNA used as a control. $(E)$ Loss of eri-6/7 results in an increase in the H3K9me3 modification on transgene sequences. Loss of the HMT set-25 results in a loss of H3K9me3. E01G4.5 is an endogenous ergo-1 and eri-6/7 target. $(F)$ Loss of eri-6/7 results in a decrease in the H3K4me3 modification on transgene sequences. (G) Multiple Argonautes and small RNA pathways act on multicopy transgenes. $(H)$ More than one-fifth of endogenous ERGO-1-ERI-6/7-NRDE-3 targets are also targeted by the Argonaute CSR-1, including E01G4.5. One-fourth of ALG-3/4 targets are also targets of CSR-1. (I) Model of transgene silencing. 
Fischer et al.

Table 1. Gene inactivations that cause a change in the somatic silencing of transgenes in wild type or the eri-6/7 mutant

\begin{tabular}{|c|c|c|c|c|}
\hline $\begin{array}{l}\text { Gene A } \\
\text { Inactivation }\end{array}$ & Gene A Description & $\begin{array}{l}\text { Gene B tested for } \\
\text { suppression }\end{array}$ & Gene B Description & $\begin{array}{l}\text { Transgene } \\
\text { expression }\end{array}$ \\
\hline - (wild type) & - & - & - & expressed \\
\hline \multicolumn{5}{|c|}{ Endogenous RNAi factors } \\
\hline $\operatorname{ergo-1}(\operatorname{tm1860)}$ & Argonaute & - & - & silenced \\
\hline eri-6/7(mg411) & helicase & - & - & silenced \\
\hline eri-6/7(mg379) & helicase & - & - & silenced \\
\hline eri-6/7(mg379) & helicase & $g \mid p-1(R N A i)$ & no germline & silenced \\
\hline nrde-3(tm1116) & nuclear Argonaute & - & - & partially silenced \\
\hline eri-6/7(mg379) & helicase & nrde-3(tm1116) & nuclear Argonaute & expressed \\
\hline wago-1(ok1074) & Argonaute & - & - & expressed \\
\hline$C S r-1(R N A i)$ & Argonaute & - & - & silenced \\
\hline \multicolumn{5}{|c|}{ Exogenous RNAi factors } \\
\hline rde-1(ne300) & Argonaute & - & - & expressed; sick \\
\hline rde-4(ne299) & dsRNA binding & - & - & expressed; sick \\
\hline$d r h-1$ (RNAi) & helicase & - & - & expressed \\
\hline eri-6/7(mg411) & helicase & $d r h-1(R N A i)$ & helicase & partially silenced \\
\hline \multicolumn{5}{|l|}{ piRNA factors } \\
\hline prg-1(tm872) & Argonaute & - & - & partially silenced \\
\hline eri-6/7(mg379) & helicase & prg-1(tm872) & Argonaute & silenced \\
\hline \multicolumn{5}{|c|}{ Chromatin modification factors } \\
\hline set-25(n5021) & H3K9 methyltransferase & - & - & expressed \\
\hline eri-6/7(RNAi) & helicase & set-25(n5021) & H3K9 methyltransferase & partially silenced \\
\hline lin-61(RNAi) & H3K9Me2/3 binding & - & - & expressed \\
\hline eri-6/7(mg411) & helicase & lin-61(RNAi) & H3K9Me2/3 binding & expressed \\
\hline dpy-30(RNAi) & Set1/MLL complex & - & - & silenced \\
\hline set-2(RNAi) & H3K4 methyltransferase, Set1 & - & - & partially silenced \\
\hline eri-6/7(mg379) & helicase & $d p y-30(R N A i)$ & Set1/MLL complex & silenced \\
\hline eri-6/7(mg379) & helicase & set-2(RNAi) & H3K4 methyltransferase, Set1 & silenced \\
\hline \multicolumn{5}{|l|}{ MicroRNA factors } \\
\hline lin-4(ma161) & microRNA targeting lin-14 & - & - & expressed \\
\hline eri-6/7(RNAi) & helicase & lin-4(ma161) & microRNA targeting lin-14 & silenced \\
\hline alg-1(gk214) & Argonaute & - & - & silenced \\
\hline eri-6/7(RNAi) & helicase & alg-1(gk214) & Argonaute & silenced \\
\hline rol-6(su1006) & rol- 6 not on $\mathrm{mg} / \mathrm{s} 30$ transgene & alg-1(RNAi) & Argonaute & rol-6 expressed \\
\hline
\end{tabular}

All mutations and RNAi knockdowns were analyzed in mgIs30 transgenic animals and scored for a rolling phenotype. (Red) Gene inactivations that cause silencing of the transgene; (blue) gene inactivations that suppress silencing of the transgene.

Argonaute ALG-1 in a wild-type background silences the transgene, as does loss of the miRNA factors VIG-1 and AIN-1, the GW182 ortholog (Table 1; see below).

Transgene silencing of single-copy foreign sequences in the germline, but not of high-copy transgene sequences in the germline, involves piRNAs that target foreign sequences and thus requires the PIWI protein PRG-1. Highcopy transgene silencing in the somatic cells of the eri-6/ 7 mutant does not require the PIWI protein PRG-1 (Table 1). In addition, a functional germline is not required for silencing in the eri-6/7 mutant: Transgenes are silenced in sterile $g l p-1$ (RNAi) animals (data not shown). These data indicate that the silencing response to somatic highcopy transgenes differs from the response to germlineexpressed low-copy transgenes; germline low-copy transgenes are silenced through a response similar to the silencing of transposable elements, involving PIWI proteins and piRNAs.

The silencing of the rol-6 transgene is suppressed by loss of NRDE-3, an Argonaute acting in nuclear RNAi
(Table 1). This suggests that transgene silencing may proceed through a nuclear silencing pathway. NRDE-3 acts in a nuclear RNAi pathway upstream of the inactive chromatin H3K9 trimethylation mark in somatic tissues (Burkhart et al. 2011). We tested whether histone H3 methyltransferases are required for transgene silencing in the eri-6/7 mutant. Whereas two members of the Set1/ MLL complex (SET-2 and DPY-30) that deposits active H3K4me3 marks are not required for silencing, SET-25, a histone H3K9 methyltransferase, and LIN-61, an MBT protein that preferentially binds $\mathrm{H} 3 \mathrm{~K} 9 \mathrm{me} 2$ and $\mathrm{H} 3 \mathrm{~K} 9 \mathrm{me} 3$, are required for silencing in somatic cells of the $\mathrm{mgIs} 30$ transgene in the eri-6/7 helicase mutant (Table 1). Gene inactivation of set-2 or dpy-30 in wild type causes silencing of the mgIs30 transgene, suggesting that the active chromatin marks conferred by these histone methyltransferases are essential for expression of foreign genetic elements from tandem arrays (Table 1). The finding that the NRDE-3/Argonaute and SET-25/H3K9HMT are required for transgene silencing in the eri-6/7 
mutant suggests that transgene chromatin may be modified to silence transgene expression. We performed chromatin immunoprecipitation (ChIP) experiments with a wild-type $m g I s 30$ transgenic strain, an mgIs 30 transgenic eri-6/7 strain (silenced transgene), and an mgIs30 transgenic set-25 strain (partially silenced transgene) using antibodies for $\mathrm{H} 3 \mathrm{~K} 9 \mathrm{me} 3$ and $\mathrm{H} 3 \mathrm{~K} 4 \mathrm{me} 3$. $\mathrm{H} 3 \mathrm{~K} 9 \mathrm{me} 3$ is found at inactive promoters and gene bodies; in C. elegans, it is also found on active genes present in heterochromatin. H3K4me3 is found on active and inactive promoters, including those of genes that may become active, and also on the first exon of active genes.

The silent mark H3K9me3 is increased on transgene sequences in the eri-6/7 mutant and reduced in the set25/HMT mutant (Fig. 1E; Supplemental Fig. 1F). The E01G4.5 gene is a known target gene of the ERGO-1ERI-6/7 endogenous RNAi pathway that is desilenced in the eri-6/7 mutant; it shows a reduction of $\mathrm{H} 3 \mathrm{~K} 9 \mathrm{me} 3$ in the eri-6/7 and set-25 mutants.

The H3K4me3 modification is found on the rol-6/ collagen exon in a wild-type transgenic strain (Fig. 1F; Supplemental Fig. 1G); in the eri-6/7 mutant, this modification is reduced. Similar results were found for the E01G4.5 gene.

These data show that loss of ERI-6/7 leads to changes in both active and inactive chromatin marks. As described below, we found that loss of the anti-silencing Argonaute CSR-1 results in transgene silencing (Table 1; Fig. 1G). We hypothesize that transgene siRNAs are bound by both the silencing Argonaute NRDE-3 (directing H3K9 trimethylation by SET-25) and the anti-silencing Argonaute CSR-1 (possibly directing H3K4 trimethylation by SET-2/DPY-30). CSR-1, ERGO-1, and NRDE-3 also act in endogenous RNAi. In an analysis of endogenous RNAi target genes, we compared CSR-1 target genes with ERGO-1 target genes and found that for more than a fifth of ERGO-1 target genes, the siRNAs are bound by not only the silencing NRDE-3/Argonaute but also the anti-silencing CSR-1/Argonaute (Fig. 1H). This is also true for the gene E01G4.5, a gene with two paralogs in the C. elegans Bristol N2 genome, all of which are absent in the genome of another C. elegans isolate, CB4856 from Hawaii (Maydan et al. 2007), but present in high copy in other Caenorhabdites: Caenorhabditis remanei and Caenorhabditis brenneri. E01G4.5 and its paralogs encode proteins with a viral DNA polymerase B2 domain, suggesting that they may be integrated DNA viruses that continue to be detected and repressed by the ERGO-1-ERI-6/7 newly acquired foreign gene surveillance pathway.

This analysis of multicopy transgene silencing shows that these transgenes produce dsRNAs that are substrates of the exogenous RNAi and antiviral defense pathway mediated by the DRH-1 helicase. ERI-6/7 is required for the efficient production or stability of $22 \mathrm{G}$ transgene siRNAs, although these ERI-6/7-dependent siRNAs are not required for silencing, as loss of ERI-6/7 results in increased transgene or exogenous RNAi silencing, presumably through the release of a limiting factor acting in the downstream steps of the silencing pathway. Transgene siRNAs may also be routed into the CSR-1 endog- enous RNAi pathway, a pathway that is thought to confer protection against silencing to its target genes (Fig. 1I; Lee et al. 2012). The balance between siRNA loading onto NRDE-3 versus CSR-1 may shift upon loss of ERI-6/7. Downstream from transgene siRNA generation, the nuclear Argonaute NRDE-3 is strictly required for silencing and directs H3K9 trimethylation by the histone H3K9 histone methyltransferase SET-25 and the H3K9me3binding MBT domain protein LIN-61, a protein that interacts with SET-25 (X Wu and G Ruvkun, unpubl.). This is accompanied by a loss of H3K4me3 marks that may have been deposited by SET-2/DPY-30, possibly directed by the Argonaute CSR-1.

\section{Identification of gene inactivations that enhance the silencing of foreign genetic elements}

To identify additional genetic components that mediate negative regulation or pathways that compete with the silencing of repetitive foreign DNA and possibly viruses, we performed a genome-wide RNAi screen for gene inactivations that enhance the silencing of the rol- $6:$ : lin-14 fusion gene on the same mgIs30 transgene characterized above. The mgIs30 transgenic strain shows a rolling phenotype caused by expression of the rol-6(su1006) mutant transgene (Supplemental Fig. 2A). The lin-14 3' UTR is a target of the lin-4 miRNA and the let-7 family of miRNAs, but normal miRNA activity of wild type is not sufficient to silence the multiple copies of the rol-6::1in14 3' UTR fusion genes on the tandemly repeated transgene array. The RNAi screen for a nonrolling phenotype was expected to reveal gene inactivations that increase the intensity of RNAi, as exemplified by eri mutants, or increase the silencing by the miRNAs that target the lin14 3' UTR present on the transgene.

Transgenic animals were exposed to dsRNAs for two generations and scored in the second generation for suppression of the rolling phenotype of the parent strain (Supplemental Fig. 2B). Ninety percent of the genes in the genome that are present in the combination of feeding RNAi libraries constructed by Ahringer and Vidal (Boulton et al. 2002; Kamath et al. 2003) were tested in duplicate in the primary screen. Gene inactivations that repressed the rolling phenotype of the $m g I s 30$ transgene were retested in quadruplicate. Positive hits were tested for genetic interactions with the rol-6 collagen gene or another cuticular collagen gene, sqt-1, using chromosomally localized mutations; gene inactivations that suppressed rol-6 and sqt-1 mutant phenotypes and thus correspond to suppressors of these collagen mutations were excluded from further analysis. The 69 remaining gene inactivations cause a suppression of the rol-6 rolling phenotype in $>35 \%$ of the animals in multiple retests (Table 2; Supplemental Fig. 2C) only when rol-6(su1006) was expressed from a transgene. More than two-thirds of the genes identified in this screen are conserved in humans (Fig. 2A; Table 2). In addition, whereas genetic screens for RNAi pathway components have mostly identified gene inactivations that do not cause developmental defects, such as arrest of development or sterility, $60 \%$ of the genes identified in this RNAi 
Fischer et al.

Table 2. Sixty-nine gene inactivations that cause enhanced silencing of the mgIs30 transgene

\begin{tabular}{|c|c|c|c|}
\hline Gene & Percent silencing & Description & Human ortholog \\
\hline$a d r-1$ & $98 \%$ & dsRNA-specific adenosine deaminase & ADARB2 \\
\hline D2005.1 & $98 \%$ & dsRNA-specific adenosine deaminase & \\
\hline$d p y-23$ & $98 \%$ & Adaptin; clathrin adaptor complex, $\mu 2$ subunit of AP2 complex & AP2M1 \\
\hline ergo-1 & $98 \%$ & Argonaute protein & EIF2C3/AGO3 \\
\hline eri-7 & $98 \%$ & Superfamily I helicase & IGHMBP2/MOV10 \\
\hline rnp-5 & $98 \%$ & Splicing factor exon-exon junction complex protein & RNPS1 \\
\hline lin-54 & $93 \%$ & DNA-binding protein; recruits DRM complex & LIN54 \\
\hline $\operatorname{lin}-9$ & $93 \%$ & Retinoblastoma pathway protein & LIN9 \\
\hline rde-4 & $93 \%$ & dsRNA-binding protein; interacts with Dicer & \\
\hline eri-6 & $93 \%$ & & \\
\hline csr-1 & $91 \%$ & Argonaute protein & EIF2C3/AGO3 \\
\hline adt-2 & $89 \%$ & Secreted metalloprotease & ADAMTS7 \\
\hline rde-12 & $89 \%$ & RNA helicase & DDX3X \\
\hline$a d r-2$ & $88 \%$ & dsRNA-specific adenosine deaminase & ADAR \\
\hline$i s w-1$ & $88 \%$ & SWI/SNF-related regulator of chromatin & SMARCA1 \\
\hline eri-12 & $85 \%$ & & \\
\hline dpy-20 & $85 \%$ & BED Zn finger protein & \\
\hline ell-1 & $85 \%$ & RNA polymerase II elongation factor & \\
\hline htz-1 & $85 \%$ & $\mathrm{H} 2 \mathrm{~A} . \mathrm{Z}$ histone $\mathrm{H} 2$ variant & H2AFZ \\
\hline T26A8.4 & $79 \%$ & Zn finger & ZC3H4 \\
\hline$s t c-1$ & $77 \%$ & ATPase similar to HSP70 superfamily; ER chaperone & HSPA13 \\
\hline suro-1 & $77 \%$ & Carboxypeptidase & $\mathrm{CPA} 2$ \\
\hline$n t 1-9$ & $76 \%$ & NOT-like, CCR4/NOT complex component & CNOT9 \\
\hline attf-3 & $73 \%$ & AT hook transcription factor & \\
\hline ekl-1 & $70 \%$ & Tudor domain protein & \\
\hline usp-5 & $70 \%$ & Ubiquitin-specific protease & USP5 \\
\hline pdi-2 & $69 \%$ & Protein disulfide isomerase & P4HB \\
\hline C35A5.8 & $68 \%$ & Nuclear export receptor; exportin & XPO7 \\
\hline prmt-1 & $68 \%$ & Protein arginine methyltransferase & HMRT1L2 \\
\hline F29A7.6 & $66 \%$ & M-phase phosphoprotein 6; exosome associated, RNA binding & MPHOSPH6/MMP6 \\
\hline Y39G10AR.7 & $66 \%$ & & \\
\hline lin-35 & $65 \%$ & Retinoblastoma protein $(\mathrm{Rb})$ & RBL2 \\
\hline$f \ln -2$ & $64 \%$ & Actin-binding cytoskeleton protein, filamin & FLNC \\
\hline mes-2 & $62 \%$ & SET domain protein; Polycomb-like repressive complex PRC2 & $\mathrm{EZH} 2$ \\
\hline sdha-2 & $62 \%$ & Succinate dehydrogenase, flavoprotein subunit & SDHA \\
\hline sams -4 or sams -3 & $60 \%$ & S-adenosylmethionine synthetase & MAT2A \\
\hline$d r h-3$ & $58 \%$ & DEAD-box helicase & IFIH1 \\
\hline tcer-1 & $58 \%$ & Transcription elongation regulator & TCERG1 \\
\hline col-90 & $56 \%$ & Collagen & COL23A1 \\
\hline ent-1 & $54 \%$ & Equilibrative nucleoside transporter & SLC29A3/hENT3 \\
\hline arl-8 & $54 \%$ & Arf-like small GTPase & ARL8B \\
\hline R186.7 & $53 \%$ & Pinin & PNN \\
\hline mel-32 & $49 \%$ & Glycine/serine hydroxymethyltransferase & SHMT1 \\
\hline T11F9.7 & $49 \%$ & & \\
\hline aps-2 & $48 \%$ & Adaptin; clathrin adaptor complex, $\sigma 2$ subunit of AP2 complex & AP2S1 \\
\hline dpy-30 & $48 \%$ & Histone H3 (Lys4) methyltransferase complex (Setlp) & DPY30 \\
\hline F57C9.7 & $48 \%$ & & \\
\hline exos-1 & $48 \%$ & Exosome component & EXOSC1 \\
\hline T24C4.2 & $45 \%$ & & \\
\hline C43H6.4 & $45 \%$ & & \\
\hline F35E8.4 & $44 \%$ & Metridin-like ShK toxin & \\
\hline $\operatorname{cog} c-5$ & $43 \%$ & Conserved oligomeric golgi complex subunit & COG5 \\
\hline ain-1 & $43 \%$ & Homolog of TNRC6A/GW182; AGO interactor & TNRC6A \\
\hline cpar-1 & $43 \%$ & CENP-A inner kinetochore histone $\mathrm{H} 3$ variant & CENPA \\
\hline T03F6.4 & $43 \%$ & & \\
\hline Y48A6B.7 & $43 \%$ & Cytosine deaminase & ADAT2 \\
\hline npp-12 & $43 \%$ & Nuclear pore complex, gp210 component & NUP210 \\
\hline$u b c-20$ & $42 \%$ & Ubiquitin-conjugating enzyme E2 K & UBE2K \\
\hline mes-3 & $41 \%$ & Member of Polycomb-like repressive complex PRC2 & \\
\hline cutl-20 & $39 \%$ & Cuticulin & \\
\hline
\end{tabular}


Table 2. continued

\begin{tabular}{lcll}
\hline Gene & Percent silencing & \multicolumn{1}{c}{ Description } & Human ortholog \\
\hline vig-1 & $39 \%$ & RNA-binding protein RISC complex, homolog of Drosphila VIG & HABP4 \\
F37A4.1 & $39 \%$ & Abhydrolase & ABHD16A \\
hgo-1 & $38 \%$ & Homogentisate 1,2-dioxygenase & HGD \\
puf-8 & $38 \%$ & PUF (Pumilio/FBF) domain-containing & PUM2 \\
C41D11.4 & $38 \%$ & & \\
apa-2 & $36 \%$ & Adaptin; clathrin adaptor complex, $\alpha$ subunit of AP2 complex & AP2A1 \\
C25F9.11 & $36 \%$ & G-protein-coupled receptor & GPR139 \\
ccr-4 & $36 \%$ & CCR4, CCR4/NOT complex component & CNOT6L \\
nurf-1 & $36 \%$ & NURF chromatin remodeling complex, subunit NURF301/BPTF & BPTF \\
\hline
\end{tabular}

Inactivation of these genes results in transgene silencing, scored as the percentage of nonrolling animals (percent silencing). Human orthologs are indicated. Orthologs in bold have been identified in a comprehensive analysis of the human mRNA interactome (Castello et al. 2012).

screen are essential for viability (Fig. 2A). These genes can be detected in functional genomic screens such as these that assay for transgene silencing in sterile or arrested animals and/or use a shorter gene inactivation period than we used for these particular gene inactivations.

The identification of several gene inactivations known to cause increased transgene silencing and/or enhanced RNAi, such as the helicase gene eri-6/7 (Fischer et al. 2008), the Argonaute gene ergo-1 (Fischer et al. 2011), the ADAR genes $a d r-1$ and $a d r-2$ (Knight and Bass 2002), and the DRM complex component lin-35/Rb (Kelly and Fire 1998; Hsieh et al. 1999), validates the ability of the screen to discover the previously identified eri genes and regulators of expression of the RNAi machinery (Wu et al. 2012). The complete set of genes identified by this screen was analyzed for known and predicted interactions as well as transcriptional coexpression. We identified multiple components of several known protein complexes that interact with chromatin, DNA, or RNA, including DRM complex genes (lin-9, lin-35, and lin-54), CCR4/ NOT complex genes (ccr-4 and ntl-9), PRC2 complex genes (mes-2 and mes-3), miRISC complex genes (alg-1, vig-1, and ain-1), and NURF complex genes (nurf-1 and isw-1). Analysis of interactions between the 69 identified genes and proteins yielded a compact functional coupling subnetwork (Alexeyenko and Sonnhammer 2009) with more links (203 links) than the set of 69 previously characterized known C. elegans small RNA pathway genes (108 links) (Supplemental Fig. 2D). The newly identified genes are enriched for genes that cluster with genes expressed in the germline and muscle/collagen, based on analysis of coexpression with genes known to function in certain tissues (Supplemental Fig. 2E; Kim et al. 2001). The subcellular localization of some of the proteins identified is known. Several reside in P granules, and many of the gene inactivations affect $\mathrm{P}$ granule structure, including csr-1/Argonaute, rde-12/F58G11.2, adr-1/ADAR, puf-8/pumilio, and npp-12/nucleoporin (Ariz et al. 2009; Updike and Strome 2009; Sheth et al. 2010).

The ERI-1/nuclease, ERI-6/7/helicase, and LIN-35/Rb are required for endogenous RNAi, negatively regulate or compete with exogenous RNAi, and are required for the somatic expression of many multicopy transgenes. To distinguish between gene inactivations that specifically silence the rol-6::1in-14 $3^{\prime}$ UTR transgene and gene inactivations that, like the eri genes, silence many multicopy transgenes, the 69 silencing gene inactivations were tested for silencing of a transgene bearing the rol-6(su1006)::rol-6 3' UTR and of five other GFP fusion transgenes with different promoters driving expression in diverse tissues and under the control of different 3' UTRs (Fig. 2B; Supplemental Table 1). Most gene inactivations (60 out of 69 tested) silence multiple transgenes, suggesting that they identify new eri genes, not negative regulators of miRNA function that could have emerged from this screen that used the rol-6::lin-14 3' UTR reporter gene (Fig. 2C; Supplemental Table 2). The nine gene inactivations that specifically silence the rol-6::1in-14 3' UTR reporter gene could identify negative regulators of miRNA function or factors that act in pathways that compete with an miRNA pathway for common factors, analogous to how the eri mutations enhance RNAi by debilitating endogenous silencing pathways. The few gene inactivations that also silence the rol-6(su1006): :rol-6 3' UTR but not other transgenes could be rol-6-specific, such as the carboxypeptidase gene suro-1 (Fig. 2C; Kim et al. 2011).

To identify factors that, like the helicase gene eri-6/7, negatively regulate exogenous RNAi, we analyzed all 69 gene inactivations for enhanced exogenous RNAi (Eri) phenotypes. In two types of RNAi assays, wild-type worms were exposed to dsRNA of one of the 69 newly identified genes from the screen and dsRNA of several tester genes; i.e., genes for which RNAi in wild type induces a weaker phenotype than the known loss-offunction phenotype (Supplemental Fig. 3A). If the candidate gene inactivation causes enhanced RNAi response, RNAi of the tester gene at the same time would cause a more severe phenotype than the control. We identified 22 eri genes by RNAi (Fig. 2B,D; Supplemental Table 3). These include known eri genes such as the helicase gene eri-6/7 (Fischer et al. 2008) and the Argonaute gene ergo-1 (Yigit et al. 2006) but also many genes that have not been previously implicated in RNAi. In parallel to the double RNAi experiments, 27 available viable mutants corresponding to a subset of the 69 gene inactivations that emerged from the genome screen were tested for enhanced RNAi (Eri) phenotypes. Fourteen mutants, about half of the strains tested, display enhanced RNAi pheno- 
Fischer et al.

A

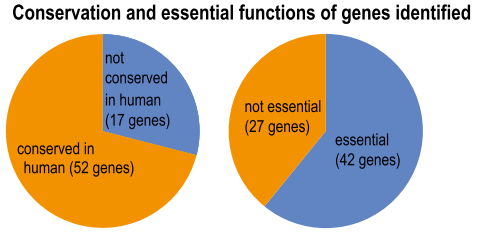

B

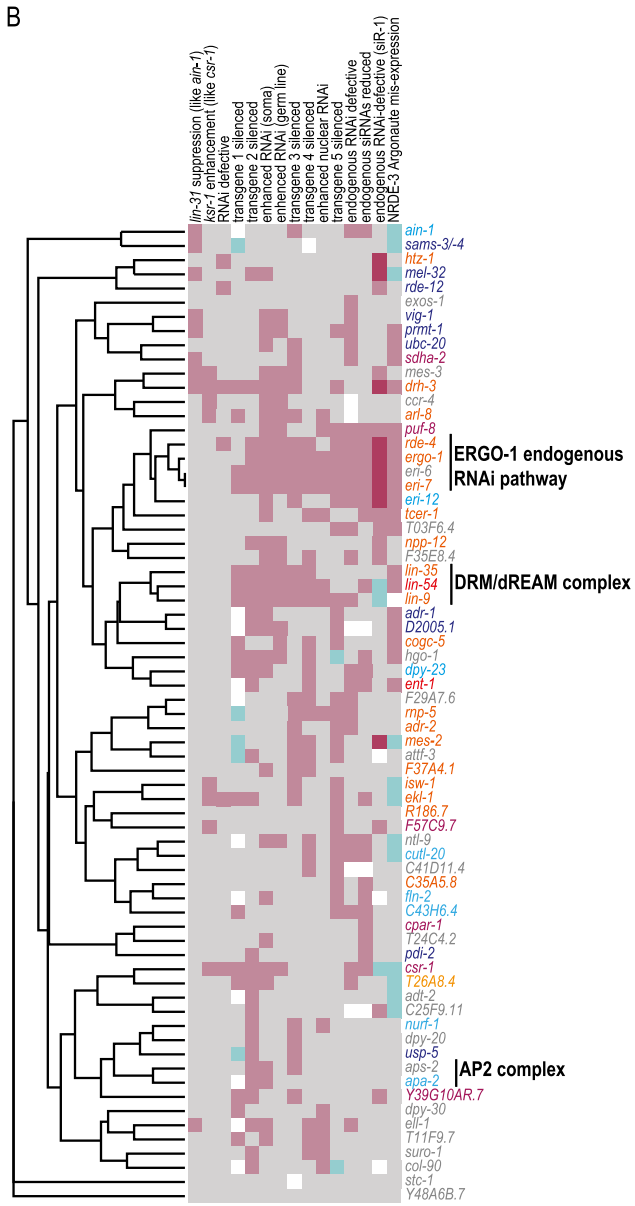

C s

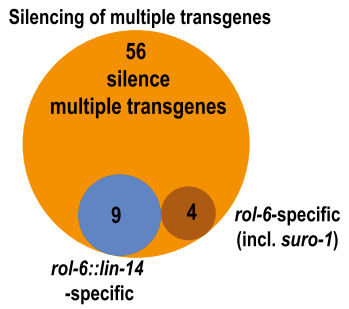

D Defects in exogenous RNAi

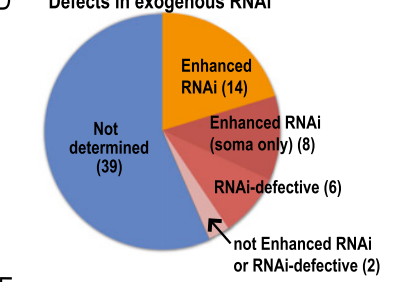

E

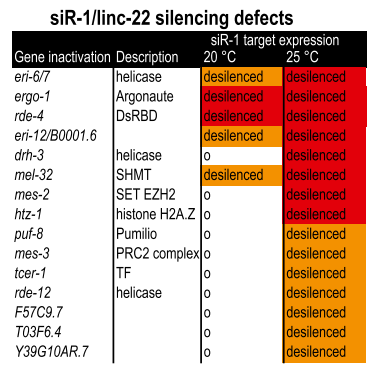

$\mathrm{F}$

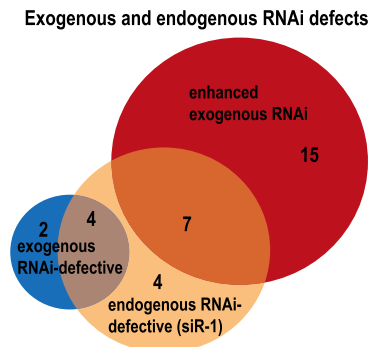

Figure 2. A whole-genome screen to identify small RNA pathway factors. (A) Most of the 69 genes identified are conserved in humans. Most of the identified genes are essential for viability. (B) Hierarchical clustering of the genes identified in the screen based on phenotypes in RNA silencing assays. The clusters described in Figure 3A are indicated in color: Cluster 1 is burgundy, clusters 1 and 2 are red, cluster 2 is orange, cluster 3 is dark blue, and cluster 4 is light blue. $(C)$ Most gene inactivations silence multiple transgenes; some gene inactivations are specific for the rol-6 gene or the lin-14 3' UTR, representing possible rol-6 interactors or enhancers of miRNA activity, respectively. (D) Many enhanced RNAi (eri) gene inactivations were identified, as well as several RNAi-defective gene inactivations $(r d e)$. (E) Genes required for the silencing of a single-copy siR-1 target transgene. Orange indicates moderate desilencing when the gene is inactivated, and red indicates strong desilencing. $(F)$. Overlap of genes acting in exogenous RNAi and endogenous siR-1 silencing. types (Fig. 2B,D; Supplemental Table 3), many of which confirmed the results of the double RNAi assays.

Five of the genes identified are known to be required for RNAi: $r d e-4 / \mathrm{dsRBD}, c s r-1 /$ Argonaute, $d r h-3 /$ helicase, ekl-1/Tudor, and htz-1/H2A.Z. Interestingly, rde-4 mutants are mostly but not completely RNAi-defective but display enhanced RNAi phenotypes when inactivated by RNAi. Similarly, whereas a transgene crossed into a strain with an rde-4 mutation is initially silenced (e.g., the mgIs30 transgene), after multiple generations, the transgene is no longer silenced. These data suggest that $r d e-4$ has multiple distinct functions, possibly in the soma and germline. We tested available viable mutants for RNAi-defective (Rde) phenotypes and assayed all 69 genes for Rde phenotypes by RNAi. We identified one new factor required for RNAi, a DEAD-box helicase protein homologous to Drosophila Vasa and Belle and human DDX3 and DDX4 that localizes to germline ribonucleoprotein P granules (Sheth et al. 2010). We named this gene rde-12.

From the suite of secondary screens, 28 out of 69 gene inactivations show altered responses to exogenous RNAi: either enhanced silencing in response to dsRNA (22 eri genes) or a lack of silencing in response to dsRNA (six rde genes).

\section{Endogenous RNAi defects caused by the newly identified gene inactivations}

Several known endogenous RNAi pathway factors were identified in the full genome screen for enhanced transgene silencing, including the genes encoding the helicases ERI-6/7 and DRH-3, the Argonautes ERGO-1 and CSR-1, and the Tudor domain protein EKL-1. Many of the currently known negative regulators of exogenous RNAi (eri genes) are required in the ERGO-1 endogenous RNAi 
pathway that targets newly duplicated genes (Fischer et al. 2011). This pathway may compete for limiting factors with the exogenous RNAi pathway and transgene silencing pathway; thus, loss of this endogenous silencing pathway may free factors to in turn enhance exogenous RNAi and transgene silencing. To test specifically for a role in endogenous RNAi, we assayed each gene inactivation for defects in endogenous RNAi silencing. We used a sensor strain that assays for the silencing activity of one abundant siRNA, siR-1, depending on the ERGO-1 pathway and downstream factors that act in multiple endogenous RNAi pathways (Montgomery et al. 2012). siR-1 targets the noncoding RNA linc-22. The sensor strain harbors a gfp transgene expressed under the control of the strong ubl-1 promoter and the ubl-1 3' UTR with an insertion of a sequence that is the reverse complement of siR-1. The silencing of this transgene is dependent on siR-1, and an otherwise identical transgene without the siR-1 target sequence is not silenced (Montgomery et al. 2012). The siR-1 endogenous siRNA is abundant in C. elegans grown at $20^{\circ} \mathrm{C}$ but is 10 -fold reduced in animals reared at $25^{\circ} \mathrm{C}$ (Supplemental Fig. 3B), allowing for more sensitive screening for factors required for endogenous siRNA-mediated silencing. We identified several new gene inactivations that disrupt silencing of this transgenic siR-1 target but do not affect expression of the transgene that lacks the siR-1 target sequence (Fig. 2B,E), including the newly identified RNAi factors eri-12 (see below) and rde-12/DEAD-box helicase. Many of the genes required for endogenous RNAi also affect exogenous RNAi (Fig. 2F).

The identified RNAi pathway genes cluster into transcriptionally coregulated groups

To study transcriptional coregulation of this set of 69 genes, we extracted for each identified gene the 100 genes most similar in expression profile using SPELL (Serial Pattern of Expression Levels Locator), a search engine that uses $\sim 150$ RNA expression data sets to find genes with similar expression profiles (Hibbs et al. 2007). Noting extensive overlap of coexpressed genes between the hits, the 69 genes were clustered using hierarchical clustering based on the overlap between the coexpressed genes (Fig. 3A). Most genes fall into four clusters, most notably a cluster (cluster 1) that contains nine genes, including the Argonaute/piwi genes csr-1 and prg-1, the pumilio gene puf-8, and the succinate dehydrogenase gene sdha-2. Within this cluster, about half of the genes that are coexpressed with each of the hits from the screen are identical. The genes mostly frequently (up to 17 times) found coexpressed with the genes identified in the screen (Supplemental Table 4) include two Argonautes, transcription factors, chromatin factors, splicing factors, nucleoporins, and RNA-binding proteins. For example, the attf-2 AT hook transcription factor is coregulated with cluster 2 and 3 genes and the $\mathrm{Zn}$ finger transcription factor somi-1 that regulates a nuclear response to the miRNA mir-84 (Hayes et al. 2011) with cluster 4 genes.

To understand how these genes are coregulated, we examined published microarray data and ChIP data and looked for promoter motifs. We found an overlap between genes regulated by the interacting proteins MEP- $1 / \mathrm{Zn}$ finger and LET-418/Mi-2 and cluster 2 genes; $\sim 50 \%$ of cluster 2 genes are enriched in ChIP experiments for MEP-1. The expression data sets that contribute most to the similarity in expression profiles for each of the clusters include germline expression profiles and $\mathrm{Mi}-2 /$ NuRD complex mutants (cluster 1), LIN-35/Rb mutants (cluster 3), and DRM complex mutants and RNAi pathway mutants (cluster 4). Motif searching confirmed the connection between enhanced silencing and the $\mathrm{Rb}$ pathway (Wu et al. 2012). We used each of these four clusters to extract the 75 genes most similar in expression profile to these gene clusters. From these genes, we searched the sequences 600 base pairs (bp) upstream for motifs using MEME and identified several upstream motifs (Fig. 3B; Supplemental Fig. 2F). Motif 1 was recently identified in the promoters of germline and oogenesis genes (Linhart et al. 2012) and ribosomal protein genes (Sleumer et al. 2012) as part of a bipartite motif, although the second element is not always present in cluster 1 promoters. This second element of motif 1 corresponds to a germline E2F-binding site (Fig. 3B; Kudron et al. 2013). Cluster 1 motif 2 is often found in close proximity to motif 1 (Supplemental Fig. 2F). We also identified an E2F motif in cluster 2 genes (Fig. 3B; Chittenden et al. 1991). E2F constitutes the DNA-binding protein of the retinoblastoma/ dREAM complex, many subunits of which emerged from the gene inactivation screen. Taken together, these data suggest that many of the genes identified are regulated by Mi-2/NuRD-like and DRM/dREAM complexes.

\section{eri-12 and ntl-9/CNOT9 are required for endogenous SiRNAs}

Multiple endogenous RNAi pathways are active in C. elegans. To place the newly identified RNAi factors into specific endogenous RNAi pathways that are characterized by specific Argonaute proteins, we subjected the 69 gene inactivations to a series of genetic and cell biological assays (Fig. 2B; Supplemental Table 2). More than half (40 of 69) of the gene inactivations show phenotypes indicative of defective endogenous RNAi pathways. Several of these were selected for further functional analysis, including the conserved genes arl-8/ ARL8 and $n t 1-9 / C N O T 9$ as well as eri-12/B0001.6, a gene that clusters with ERGO-1 pathway genes in our phenotypic analysis (Figs. 2B; 4A).

The gene B0001.6 encodes a protein of unknown function with orthologs in nematodes. Consistent with a function in RNAi, the B0001.6 protein was identified as an interactor of the RNAi pathway gene RDE-10 by tandem mass spectrometry analysis of proteins that immunoprecipitate with RDE-10 (Zhang et al. 2012). We obtained two B0001.6 mutants: a transposon insertion that disrupts a splice site required for splicing of the 5' UTR to the first exon (Supplemental Fig. 3C) and a missense mutation, gk214100 (G206E). Both of these mutants recapitulate the enhanced RNAi phenotype observed in double RNAi experiments (Fig. 4B); hence, we named this gene eri-12. 
A

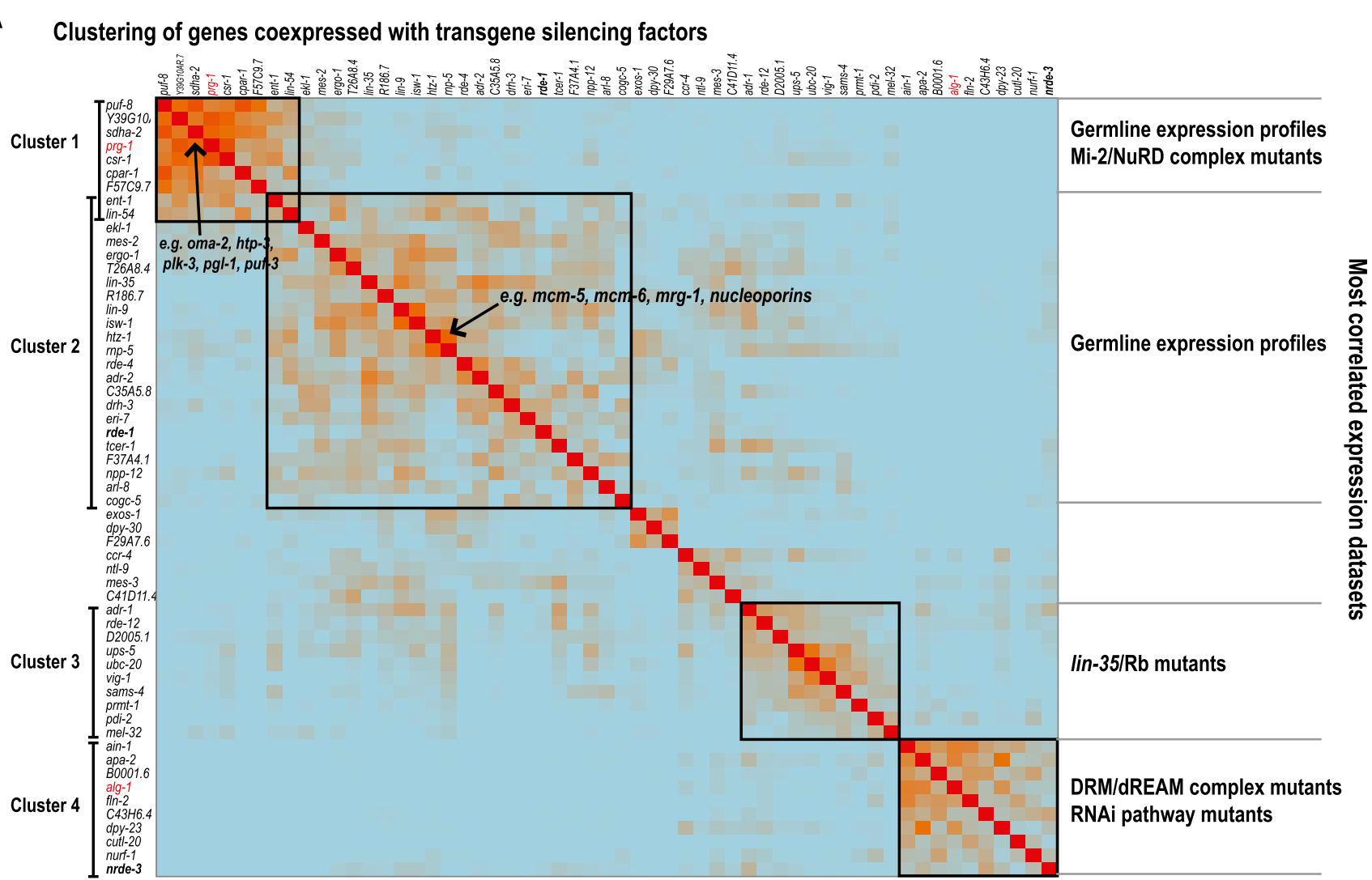

$\begin{array}{lllllllllllll}0 & 5 & 10 & 15 & 20 & 25 & 30 & 35 & 40 & 45 & 50 & 55 & 100\end{array}$

$\%$ overlap between 100 genes most correlating in expression

B

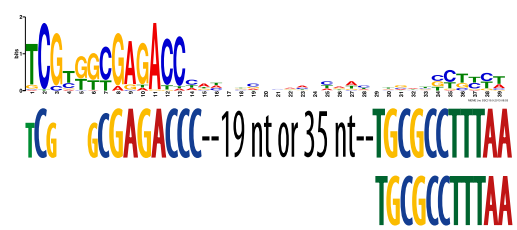

Cluster 1 Motif 1

(4.3e-122; in 46 sites in $41 / 72$ promoters within 600 bp of ATG)

Germline, oogenesis and ribosomal protein genes (Linhart et al 2011, Sleumer et al 2012); prg-1; pgl-1; sdha-2 (17/72 cluster 1 genes)

Germline E2F motif (Kudron et al 2013)

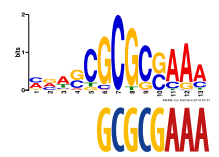

Cluster 2 Motif 1

(8.4e-034; 47 sites in 29/49 promoters within 500 bp of ATG); isw-1, htz-1, lin-9, lin-35

Consensus Mammalian E2F binding site (Chittenden et al 1991)

Figure 3. The 69 genes identified in the screen cluster based on overlap in coexpressed genes. $(A)$ Hierarchical clustering of genes coexpressed with each of the 69 genes identified in the screen. Indicated in color is the percentage of overlap between the 100 genes most similar in expression profile for each pair of genes identified in the screen. The clusters of genes that share many coexpressed genes are indicated. $(B)$ Two motifs identified in cluster 1 and cluster 2 genes and in the genes most similar in expression profile to these genes.

Loss of the gene eri-12 causes a strong siR-1 sensor desilencing phenotype similar to the phenotype observed after inactivation of the known ERGO-1 pathway components (Fig. 2E). To determine whether eri-12 is required for silencing of target mRNAs of the ERGO-1 pathway, we assayed for levels of target genes of endogenous siRNAs in the eri-12 mutant. Using qRT-PCR, we found that the eri-12 mutant fails to completely silence ERGO-1 pathway targets (Fig. 4C). Using qRT-PCR, we also found that the eri-12 mutant has reduced levels of endogenous
siRNAs that depend on ERGO-1 (Fig. 4D). These results show that eri-12 acts in the ERGO-1 endogenous RNAi pathway and is required for endogenous siRNA biogenesis. Downstream from siRNA production, the Argonaute protein NRDE-3 associates with ERGO-1 pathway siRNAs and translocates to the nucleus to mediate nuclear RNAi. A loss of ERGO-1 pathway siRNAs causes a shift in NRDE-3::GFP fluorescence from the nucleus to the cytoplasm (Guang et al. 2008). Loss of eri-12 results in a reduction in nuclear NRDE-3::GFP signal (Fig. 4E), indicat- 
A

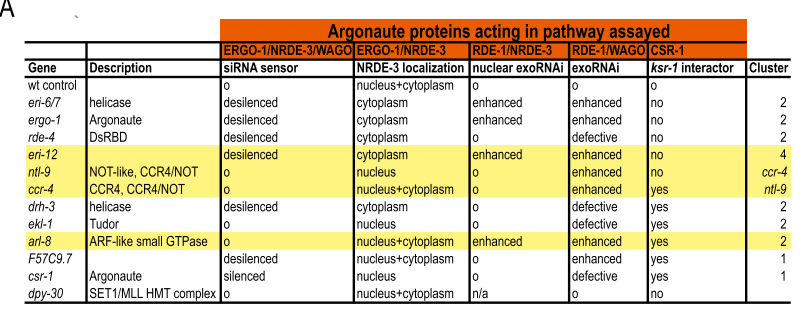

B
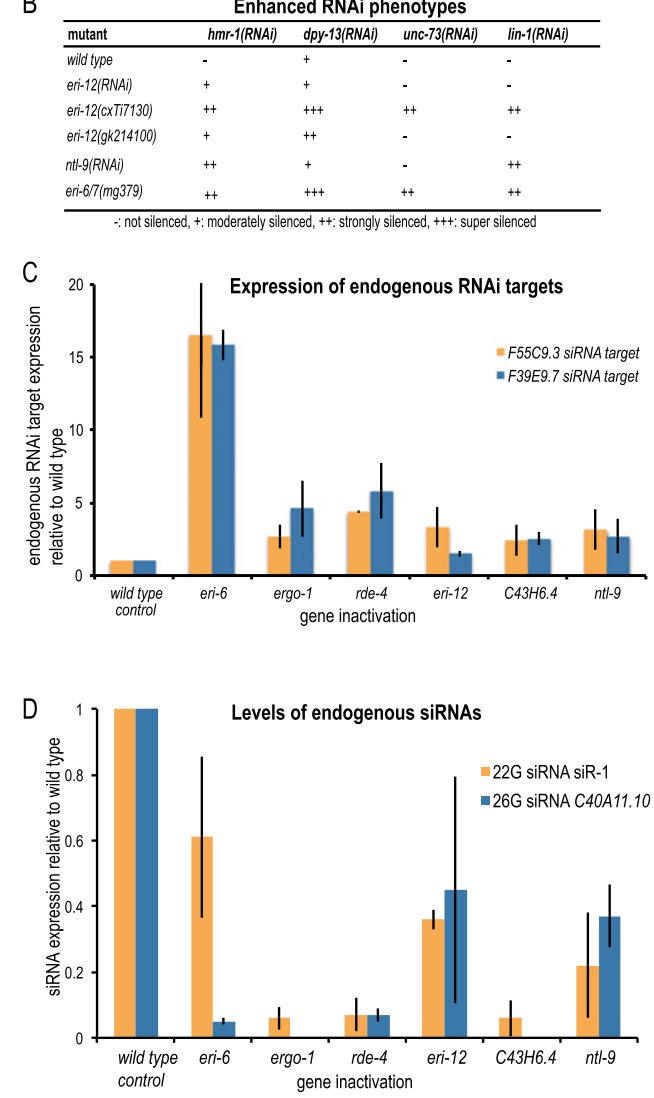

E NRDE-3/Argonaute localization

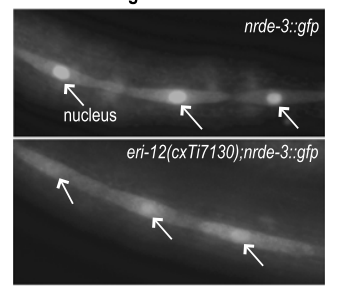

$F$ Overlap in genes co-regulated with eri-12, nrde-3 and C43H6.4

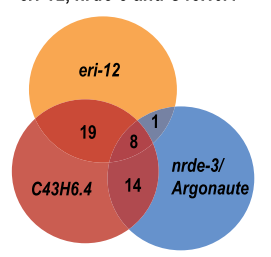

Figure 4. Characterization of new factors in the ERGO-1-ERI6/7 endogenous RNAi pathway. (A) Selected genes and their reduction-of-function phenotypes in assays for different RNAi pathways. Indicated in yellow are genes described in more detail here and in Figure 5. (B) eri-12 and ntl-9 inactivation enhances exogenous RNAi efficacy in RNAi assays targeting the genes hmr-1, dpy-13, unc-73, and lin-1. (C) eri-12, ntl-9, and C43H9.6 affect expression of endogenous siRNA targets (F55C9.3 and F39E9.7) as determined by qRT-PCR. (D) eri-12, ntl-9, and C43H9.6 affect endogenous siRNA (22G siR-1 and 26G-O1 [C40A11.10]) levels as measured by qRT-PCR. (E) Loss of eri12 causes a reduction of nuclear localized NRDE-3/Argonaute. $(F)$ Overlap between genes transcriptionally coregulated with eri-12, C43H6.4, and nrde-3. ing a loss of siRNAs binding to NRDE-3 to direct H3K9 trimethylation.

Several other newly identified genes appear to act in the ERGO-1-ERI-6/7 endogenous RNAi pathway, including C43H6.4, a gene conserved in nematodes encoding a protein with an Armadillo-type fold. Like eri-12, loss of C43H6.4 results in a reduction of ERGO-1 pathway silencing (Fig. 4C) caused by a loss of ERGO-1-ERI-6/7dependent siRNAs (Fig. 4D). eri-12, C43H6.4, and nrde-3 share expression profiles with an overlapping set of genes, indicative of a potential interaction between these genes (Fig. 4F). Similar to eri-12 and C43H6.4, inactivation of the gene $n t l-9$, one of several CCR4/NOT complex genes identified (Supplemental Table 8), results in defects in the ERGO-1-ERI-6/7 endogenous RNAi pathway (Fig. 4B-D).

\section{The ARF-like GTPase ARL-8 acts in the multiple endogenous RNAi pathways}

Using genetic interaction analyses, we assayed the gene inactivations for a role in endogenous RNAi pathways other than the ERGO-1 pathway (Fig. 4A). Genes acting in the CSR-1 endogenous RNAi pathway are known to interact with Ras pathway genes. We tested for enhancement of the ksr-1(n2526) mutant and found several gene inactivations (including arl-8) that enhance the penetrance of L1 lethality of this mutant (Fig. 4A). The arl-8 gene scored positive as a negative regulator of exogenous RNAi in both double RNAi assays and tests of mutations in the gene, tm2472 and tm2388. arl-8 encodes a conserved small GTPase that functions in endosome-tolysosome transport. In the genome-wide screen, we identified several other endocytosis genes (including $d p y-23$, apa-2, and aps-2) that function in clathrin-dependent endocytosis. We rescreened a small set of endocytosis genes for transgene silencing using a protocol that uses a shorter exposure to dsRNA to allow for the identification of lethal genes. From this screen, we identified rme-4 and rab-7 (Fig. 5A), encoding another GTPase acting in endosome-to-lysosome trafficking.

Because most of the endocytosis genes are essential, we focused on arl-8, for which viable reduction-of-function alleles are available (Klassen et al. 2010). The enhanced RNAi phenotype suggested that arl-8 functions in RNAi. Using deep-sequencing analysis, we determined the levels of the siR-1 siRNA, which is dependent on most known RNAi pathway genes, and found that this siRNA is reduced by $50 \%$ (Fig. 5B). In an analysis of all known classes of $C$. elegans siRNAs, we found that antisense siRNAs targeting ERGO-1-ERI-6/7 target genes and ALG-3/4 target genes are reduced by $25 \%-40 \%$ in the nonnull arl- 8 mutant (Fig. 5C; Supplemental Fig. 4A,B,D). Two types of siRNAs act in the ERGO-1 and ALG-3/4 pathways: 26G primary siRNAs and 22G secondary siRNAs. arl-8 affects 26G siRNA levels: More than half of the abundant (>1 RPM) 26G siRNAs are more than threefold reduced as compared with $<5 \%$ of non-26G siRNAs in the mutant (Fig. 5D). ERGO-1 target genes that produce higher levels of siRNAs are more affected by reduced ARL-8 (Supplemental Fig. 4B). Whereas loss of ERI-6/7 results in a general 
Fischer et al.

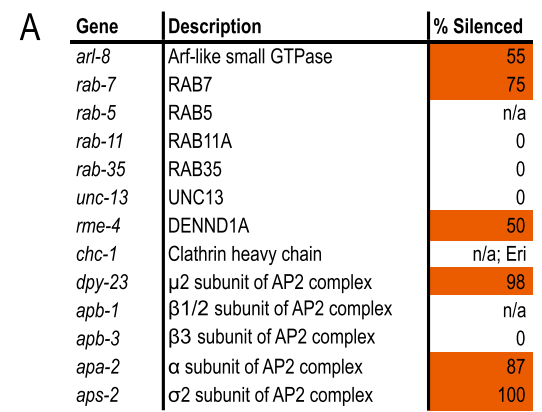
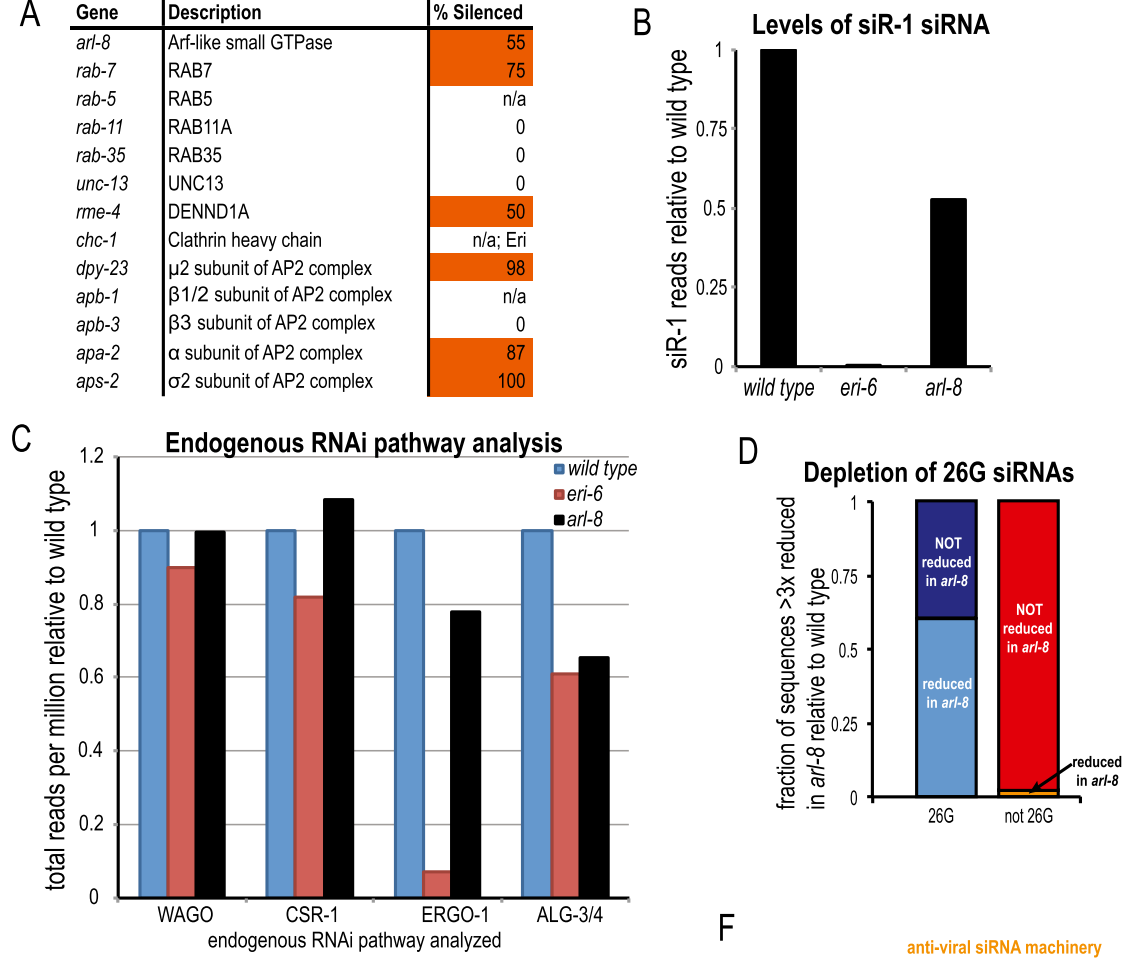

\section{$E$}

$22 \mathrm{G}$ versus $26 \mathrm{G}$-producing ALG-3/4 target genes
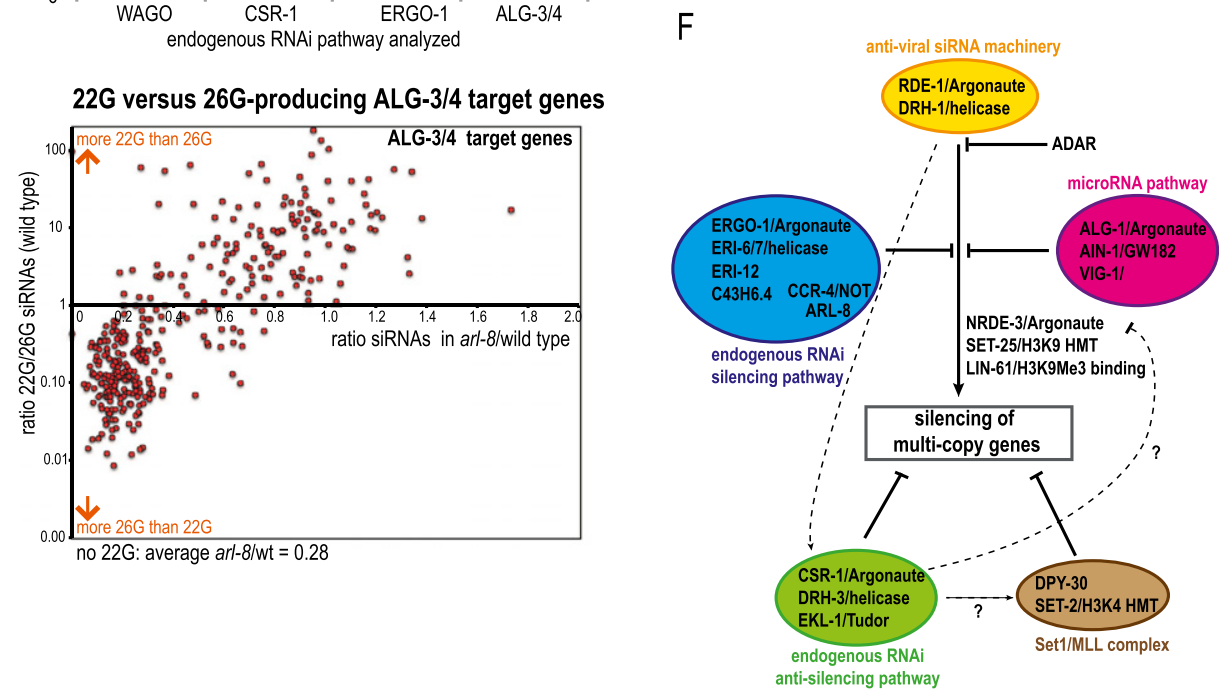

Figure 5. ARL-8 acts in endogenous RNAi. $(A)$ Inactivation of endocytosis genes increases transgene silencing. Indicated in orange are gene inactivations that enhance somatic transgene silencing. "n/a" indicates that the phenotype could not be scored because of lethality. chc-1/clathrin (RNAi) is lethal, but a temperature-sensitive chc-1 mutant displays Eri phenotypes. (B) Reduced levels of siR-1 in an arl-8 mutant as determined by deep sequencing. $(C)$ arl-8 mutation affects endogenous siRNAs in the ERGO-1 pathway and the ALG-3/4 pathway. (D) arl-8 is required for most 26G siRNAs but not for 22G siRNAs. (E) arl-8 is required for siRNAs of ALG-3/4 target genes that produce mostly 26G siRNAs. (F) A model of how the different silencing pathways and factors identified affect transgene silencing.

moderate reduction of ALG-3/4 target siRNA levels (Fig. $5 \mathrm{C}$; Supplemental Fig. 4C), a subset of ALG-3/4 target genes is strongly affected in arl-8 mutants (Supplemental Fig. 4D). We found that ALG-3/4 target genes fall into two classes: One class of genes is targeted by a single 26G siRNA either close to the start codon or targeting the $3^{\prime}$ UTR, and other ALG-3/4 target genes are targeted by multiple siRNAs distributed over the gene, including secondary 22G siRNAs. The ALG-3/4 target genes most depleted for siRNAs in arl-8 are genes that mostly produce
26G siRNAs (Fig. 5E). We found that siRNAs corresponding to a subset of ALG-3/4 target genes are enriched in CSR-1 immunoprecipitation experiments $($ Fig. $1 \mathrm{H}$; Claycomb et al. 2009). Thus, CSR-1 may act in parallel with or downstream from ALG-3/4. arl-8 affects siRNAs of ALG-3/4 targets that are not routed to the CSR-1 Argonaute (Supplemental Fig. 4E).

arl-8 encodes a small GTPase that functions in endosome-to-lysosome transport. In plants, ARL8 is also an essential host factor for tomato mosaic virus RNA replication that occurs at membranes. It interacts with 
the viral superfamily I helicase and RdRP protein. Similarly, ARL-8 may interact with the ERI-6/7 superfamily I helicase (with which it shares a set of coexpressed genes) (Fig. 3A; Supplemental Fig. 4F) and the RRF-3 RNAdependent polymerase to promote $26 \mathrm{G}$ siRNA biogenesis or stability.

\section{Discussion}

Transgenes in many organisms are silenced and produce siRNAs that mediate RNAi-based silencing. Like transposons and viruses, upon cell entry, transgenes may be recognized as foreign and targeted by the RNAi pathway. However, the silencing continues every generation after the initial injection of transgenes, as if a "foreign" signal is continually regenerated. Our deep RNA sequencing analysis revealed that only particular segments of the transgene are surveilled in this way, with siRNAs particularly concentrated in the lin-14 3' UTR of the fusion gene. One interpretation of the $3^{\prime}$ UTR location of many of the transgene siRNAs is that the ribosome "clears" the mRNA of siRNAs in the coding region. Another interpretation is that endogenous miRNAs that target these $3^{\prime}$ UTRs may attract the synthesis of secondary 22G siRNAs in a manner similar to how primary siRNAs trigger the production of secondary siRNAs, although the normal silencing that we observed in the absence of miRNA function did not support this hypothesis. In fact, we found that loss of the miRNA factors ALG-1/Argonaute, AIN-1/GW182, and VIG-1 causes increased transgene silencing. It is possible that the miRNA machinery competes with the siRNA machinery for the lin-14 3' UTR or another limiting common factor. Alternatively, ALG-1 may bind 3' UTR transgene siRNAs generated by Dicer and silence the transgene post-transcriptionally. VIG-1 was found in immunoprecipitation experiments for the RNAi factor RDE-10, suggesting that miRNA and RNAi factors may interact.

The production of siRNAs from the foreign transgene depends on the antiviral silencing factors RDE-1/Argonaute and DRH-1/helicase and paradoxically on ERI-6/7/ helicase, a gene inactivation that causes increased transgene silencing. Silencing also depends on the nuclear factors NRDE-3/Argonaute, LIN-61, and SET-25/HMT. Silencing of the transgene in the ERI-6/7/helicase mutant is accompanied by changes in transgene chromatin modifications: an increase in the trimethyl-H3K9 mark and a decrease in the trimethyl-H3K4 mark. This suggests that transgene siRNAs are bound by NRDE-3 to direct the trimethylation of histone $\mathrm{H} 3$ at $\mathrm{K} 9$ to cause transcriptional silencing. The reduction in transgene siRNAs in the eri-6/7 mutant may be a result of transcriptional gene silencing so that there is a resulting reduction in the mRNA template for siRNA generation. Alternatively, the ERI-6/7 helicase may be directly involved in the biogenesis or stability of a subset of the transgene siRNAs. Finally, transgene siRNAs could be destabilized upon loss of the ERGO-1-ERI-6/7 endogenous RNAi pathway. Upon loss of the ERGO-1-ERI-6/7 endogenous RNAi pathway, more NRDE-3/Argonaute may be available to bind transgene siRNAs that in wild type interact with other Argonautes. siRNAs of a subset of ERGO-1-ERI-6/7 endogenous siRNA targets are bound by both NRDE-3 and CSR-1, and we hypothesize that transgene siRNAs also are bound by multiple Argonaute proteins. Thus, CSR-1 may act in parallel with NRDE-3 or other WAGO proteins, downstream from RDE-1. Hence, in the absence of CSR-1, more transgene siRNAs may be bound by NRDE-3 to more effectively silence transgenes.

Inactivation of $d p y-30$ and set- 2 causes enhanced transgene silencing. Thus, the SET1/MLL complex is likely to deposit activating $\mathrm{H} 3 \mathrm{~K} 4 \mathrm{me} 3$ marks on nonsilenced transgenes, possibly directed by the anti-silencing Argonaute CSR-1. Other gene inactivations identified in our screen for enhanced transgene silencing may also act in promoting active transcription. NURF-1 is the ortholog of $\mathrm{BPTF}$, a factor that binds $\mathrm{H} 3 \mathrm{~K} 4 \mathrm{me} 3$ to recruit active transcription factors; ELL-1 is an RNA polymerase elongation factor; and TCER-1 and PUF- 8 interact to posttranscriptionally maintain levels of certain germline mRNAs (Pushpa et al. 2013). CSR-1 was recently identified as an interactor of FBF-1, a paralog of PUF-8, to attenuate translation elongation (Friend et al. 2012).

Negative regulators of exogenous RNAi could be genes that act in competing endogenous small RNA pathways, as exemplified by the ERGO-1-ERI-6/7 pathway that silences duplicated genes (Fischer et al. 2011). Several newly identified genes negatively regulate exogenous RNAi and act in the ERGO-1-ERI-6/7 endogenous RNAi pathway, including C43H6.4, the CCR-4/NOT complex gene $n t 1-9 / C N O T 9$, and eri-12. The ERI-12 protein forms a complex with the RNAi factor RDE-10. Besides canonical RNA-binding proteins such as the RDE-12/helicase, we identified several metabolic enzymes that have been identified as (candidate) mRNA-binding proteins in human cells: SDHA-2/SDHA, MEL-32/SHMT2, and PDI-2/ P4HB (Castello et al. 2012).

We found that several genes that function in endocytosis, specifically factors acting in clathrin-mediated endocytosis, are among the genes identified in the RNAi screen for enhanced transgene silencing. These are the gene inactivations that are the most pleiotropic in our screen, causing slow development and decreased brood sizes. However, they are specific in that many other gene inactivations that cause such pleiotropic developmental defects have no transgene silencing phenotype. The endosomal pathway is required for RISC formation and turnover, with RISC localizing to multivesicular bodies (MVBs) in addition to P bodies (Gibbings et al. 2009; Lee et al. 2009). The endocytic pathway has also been implicated in the uptake of dsRNA in Drosophila (Saleh et al. 2006). We found that the arl-8/Arf-like GTPase is required for wildtype levels of 26G siRNAs in two endogenous RNAi pathways and may promote 26G siRNA biogenesis.

Our screen for gene inactivations that enhance transgene silencing identified numerous additional small RNA pathway factors (Fig. 5F): factors acting in three endogenous RNAi pathways, factors enhancing exogenous RNAi, factors required for exogenous RNAi, and factors regulating expression of RNAi factors (Wu et al. 2012). Many of these genes are conserved in humans and are 
essential for viability. A subset of the genes identified is expressed in the germ line and regulated by E2F, Mi-2/ NuRD complex factors, and DRM/dREAM complexes. Overlap of the genes coexpressed with each of the genes identified in the screen was used to identify clusters of genes that may act in distinct aspects of transgene silencing. Often, genes that encode proteins that act in one protein complex cluster together, such as CCR-4 and NTL-9; LIN-9, LIN-35, and LIN-54; DRH-3 and EKL-1; APA-2 and DPY-23; and ALG-1 and AIN-1. Also, genes that cluster together based on phenotype tend to cluster in the same coexpression clusters (Fig. 2B). Thus, we identified a large set of genes that act in distinct aspects of small RNA silencing. Our data also point to extensive interactions between small RNA pathways.

\section{Materials and methods}

\section{C. elegans growth and handling; strains used}

All experiments were performed at $20^{\circ} \mathrm{C}$ unless stated otherwise. The genome-wide RNAi screen was done using strain GR1703 [lim-6::gfp, col-10::1acZ::1in-14, and rol-6(su1006)::1in-14 3' UTR]. For deep-sequencing analysis, see the complete list of strains in Supplemental Table 5. arl-8(tm2472) and arl-8(tm2388) are 3' UTR deletions. arl-8 mRNA levels are twofold reduced in $t m 2472$ versus wild type $t m 2388$ has been shown to be a reduction-of-function allele (Klassen et al. 2010).

\section{Genome-wide screen for transgene silencing}

Embryos of strain GR1703 (mgIs30) were isolated by treatments with bleach; five embryos were plated onto 12-well RNAi plates and seeded in duplicate with E. coli HT115-expressing dsRNA for each of the 18,371 genes represented in the Ahringer (Fraser et al. 2000) and Vidal (Rual et al. 2004) libraries. Plates were placed at $22^{\circ} \mathrm{C}$. $\mathrm{F} 1$ progeny of these animals were scored at the L3/L4 larval stages for the percentage of animals that display the phenotype of a silenced transgene; i.e., a non-Rol phenotype. 0: $0 \%$ non-Rol; $1:<20 \%$ non-Rol; $2:>20 \%$ non-Rol; $3:>50 \%$ nonRol; and 4: $>95 \%$ non-Rol. Five-hundred-sixty-eight genes $3 \%$ of C. elegans genes) with scores $>2.5$ were retested in four times. Ninety-three genes (16\% of genes retested) retested in two out of four retests and three out of six total tests with an average score $>2.5$ (35\% silenced) and were selected for further characterization. rol-6 interactors were excluded from further analysis. The remaining 69 RNAi clones were sequenced to confirm the identity of the gene targeted. The negative control (dsRNA not targeting a C. elegans gene) was scored 438 times and scored an average of $2 \%$ non-Rol with a maximum of $10 \%$ non-Rol. For two gene inactivations, the RNAi clone targeted two highly homologous duplicated genes: sams-3/sams-4 and $a d r-1 /$ D2005.1. For sams-3/4, we were unable to determine which gene inactivation was causal, since the DNA sequence identity is $100 \%$ for most of the gene, and therefore we indicate the hit as "sams-3/ 4." For $a d r-1$ and D2005.1, we analyzed mutants and observed silencing phenotypes for both and therefore included both.

\section{Secondary assays by RNAi}

All assays were done in at least duplicate.

Genetic interaction with HE1006(rol-6(su1006)) and GR1200(sqt1(sc13)) was tested by exposing these worms to the dsRNA of the
93 strong positives. The genes that interacted with rol-6 and/or sqt-1 were excluded from further analysis, leaving 69 genes for further analysis.

Transgene silencing assays were all done at $22^{\circ} \mathrm{C}$; these assays were done as described above for GR1703. Transgenes are described in Supplemental Table 1.

ksr-1 enhancement (Rocheleau et al. 2005) and lin-31 suppression (Ding et al. 2005) were tested using feeding RNAi of the 69 positives to ksr-1(n2526) and lin-31(n1053) mutants at $20^{\circ} \mathrm{C}$ and $25^{\circ} \mathrm{C}$, respectively, scoring the next generation for rod-like $\mathrm{L} 1$ lethals and the presence of a single vulva or no vulva, respectively; $k s r-2$ (RNAi) and ain-1(RNAi) were used as positive controls.

To test for an enhanced RNAi response, two experimental setups were used in which the worms were exposed to RNAi by feeding of two genes: the Eri tester gene and each of the 69 positives from the screen ("gene of interest"). In sequential RNAi experiments, wild-type $\mathrm{N} 2$ worms were exposed first to the gene of interest from the L1 stage until the next-generation L1 stage; subsequently, the L1 worms were moved onto Eri tester plates for unc-73, hmr-1, and lin-1 and scored in the next generation as embryos (hmr-1) or young adults (unc-73 and lin-1). In simultaneous RNAi-by-feeding experiments, worms were exposed to mixed E. coli RNAi-by-feeding lawns that contain a ratio of $4: 1$ of gene of interest:Eri tester RNAi; L1 larvae were placed on these lawns and scored in the next generation as embryos (hmr-1).

In all enhanced RNAi assays and the siR-1 sensor desilencing assay, the phenotypes were compared with the positive control (eri-6/7) and the negative control (wild type) and reported relative to these controls.

\section{Mutant analyses of exogenous RNAi responses}

Enhanced RNAi (Eri) assays and assays for RNAi-defective (Rde) phenotypes were performed as described previously (Tabara et al. 1999; Fischer et al. 2008) using feeding RNAi for lin-1, unc-73, dpy-13, unc-33, hmr-1, unc-22, and pos-1. Animals were plated as starved L1 larvae and scored as adults (hmr-1 and pos-1 for progeny) or in the next generation (other clones). All assays were done at least twice and in duplicate. In all enhanced RNAi assays, the phenotypes were compared with the positive control (eri-6/7) and the negative control (wild type) and reported relative to these controls.

\section{ChIP}

ChIP-qPCR was done as described (Guang et al. 2010) using 72-h adults and anti-trimethyl-H3K9 (Lys9) antibody (Milllipore, catalog no. 07-523) or anti-trimethyl-H3K4 (Lys9) (Abcam, catalog no. ab8580). The rol-6 primers are specific for the su1006 mutation.

\section{RNA isolation}

Large-scale total RNA was isolated by dounce homogenization in RNA-Bee (Tel-Test) followed by chloroform extraction and isopropanol precipitation. Small-scale total RNA isolations were done in Trizol using pestles in eppendorf tubes to homogenize the embryos/worms.

\section{qRT-PCR on endogenous RNAi target genes}

For qRT-PCR, total RNA from embryos and/or young adults was DNase-treated using the Turbo DNA-free kit (Applied Biosystems). cDNA was synthesized using RETROscript (Ambion) following the vendor's protocol. qPCR was done in triplicate with a CFX96 machine (Bio-Rad) using iQ SYBR Green Supermix (Bio-Rad). Relative mRNA levels were calculated based on the 
$2^{-\Delta \Delta \mathrm{ct}}$ method using the gene Y45F10D.4 for normalization. Two or three biological replicates were done for each PCR. The error bars indicate the standard error between the biological replicates. Primer sequences are listed in Supplemental Table 6.

\section{TaqMan qRT-PCR to detect small RNAs}

TaqMan qRT-PCR and data analysis were carried out as described (Han et al. 2009). Total RNA was extracted from embryos and 52- to 56-h post-hatching L4/young adult worms. At least two biological replicates were done for each assay. The error bars indicate the standard error calculated for the biological replicates. The TaqMan assays are described in Supplemental Table 7.

\section{Small RNA sequencing}

Total RNA was isolated from embryos. Eighteen-nucleotide to 28-nt small RNAs were size-selected, tobacco acid pyrophosphatase-treated to remove $5^{\prime}$ di- and triphosphate groups, ligated to $5^{\prime}$ and $3^{\prime}$ adapters, and subjected to RT-PCR according to the protocol by Gu et al. (2009). Small RNA amplicons were sequenced using an Illumina genome analyzer.

\section{Small RNA data analysis}

Data analysis was done as described (Shi et al. 2013). Briefly, small RNA sequences were parsed and mapped to the C. elegans genome (WormBase release WS230) and transgene sequences. Small RNA reads from each library were normalized to the total number of mapped reads. The numbers of small RNA reads for small RNA sequences mapping to multiple positions in the genome or transgene sequence were divided by the corresponding number of genomic loci.

\section{Bioinformatics}

FunCoup (Alexeyenko and Sonnhammer 2009) was used to analyze interactions between genes and gene products at a confidence cutoff of 0.10. Using SPELL (Hibbs et al. 2007), other positives or known small RNA pathway genes that fall within the first 100 genes with the most similar expression profiles were identified. Expression mountains (microarray "topology map" positions) were determined for each gene (Kim et al. 2001). $P$-values were calculated using hypergeometric distribution analysis.

\section{Accession numbers}

Small RNA Illumina deep-sequencing data are available at the Gene Expression Omnibus (accession nos. GSE52785 and GSE32366).

\section{Acknowledgments}

We thank Shohei Mitani and the National Bioresource Project (Japan) for deletion strains, and the Caenorhabditis Genetics Center for strains. We thank Dennis Kim, Yuval Tabach, and Xiaoyun Wu for advice and discussions, and Tai Montgomery for reagents. This work was supported by National Institutes of Health grant GM44619 (to G.R.), Leukemia and Lymphoma Society Career Development Post-doctoral Fellowship 5560-05 (to S.E.J.F.), EMBO Long-Term Fellowship ALTF 929-2003 (to S.E.J.F.), and Massachusetts General Hospital Executive Committee of Research Fund for Medical Discovery fellowship awards (to C.Z. and S.E.J.F). S.E.J.F. and G.R. conceived and designed the experiments. S.E.J.F., Q.P., P.C.B., and C.Z. performed the experiments. S.E.J.F. analyzed the data. Y.Q. and Z.S. provided scripts for data analysis. S.E.J.F. and G.R. wrote the paper.

\section{References}

Alexeyenko A, Sonnhammer ELL. 2009. Global networks of functional coupling in eukaryotes from comprehensive data integration. Genome Res 19: 1107-1116.

Ambros V, Lee RC, Lavanway A, Williams PT, Jewell D. 2003. MicroRNAs and other tiny endogenous RNAs in C. elegans. Curr Biol 13: 807-818.

Arico JK, Katz DJ, Van Der Vlag J, Kelly WG. 2011. Epigenetic patterns maintained in early Caenorhabditis elegans embryos can be established by gene activity in the parental germ cells. PLoS Genet 7: e1001391.

Ariz M, Mainpal R, Subramaniam K. 2009. C. elegans RNAbinding proteins PUF-8 and MEX-3 function redundantly to promote germline stem cell mitosis. Dev Biol 326: 295304.

Bagijn MP, Goldstein LD, Sapetschnig A, Weick E-M, Bouasker S, Lehrbach NJ, Simard MJ, Miska EA. 2012. Function, targets, and evolution of Caenorhabditis elegans piRNAs. Science 337: 574-578.

Boulton SJ, Gartner A, Reboul J, Vaglio P, Dyson N, Hill DE, Vidal M. 2002. Combined functional genomic maps of the C. elegans DNA damage response. Science 295: 127-131.

Burkhart KB, Guang S, Buckley BA, Wong L, Bochner AF, Kennedy S. 2011. A pre-mRNA-associating factor links endogenous siRNAs to chromatin regulation. PLoS Genet 7: e1002249.

Castello A, Fischer B, Eichelbaum K, Horos R, Beckmann BM, Strein C, Davey NE, Humphreys DT, Preiss T, Steinmetz LM, et al. 2012. Insights into RNA biology from an atlas of mammalian mRNA-binding proteins. Cell 149: 1-14.

Chittenden T, Livingston DM, Kaelin WG Jr. 1991. The T/E1Abinding domain of the retinoblastoma product can interact selectively with a sequence-specific DNA-binding protein. Cell 65: 1073-1082.

Claycomb JM, Batista PJ, Pang KM, Gu W, Vasale JJ, van Wolfswinkel JC, Chaves DA, Shirayama M, Mitani S, Ketting RF, et al. 2009. The Argonaute CSR-1 and its 22G-RNA cofactors are required for holocentric chromosome segregation. Cell 139: 123-134.

Conine CC, Batista PJ, Gu W, Claycomb JM, Chaves DA, Shirayama M, Mello CC. 2010. Argonautes ALG-3 and ALG-4 are required for spermatogenesis-specific 26G-RNAs and thermotolerant sperm in Caenorhabditis elegans. Proc Natl Acad Sci 107: 3588-3593.

Ding L, Spencer A, Morita K, Han M. 2005. The developmental timing regulator AIN-1 interacts with miRISCs and may target the argonaute protein ALG-1 to cytoplasmic P bodies in C. elegans. Mol Cell 19: 437-447.

Duchaine TF, Wohlschlegel JA, Kennedy S, Bei Y, Conte D, Pang K, Brownell DR, Harding S, Mitani S, Ruvkun G, et al. 2006. Functional proteomics reveals the biochemical niche of C. elegans DCR-1 in multiple small-RNA-mediated pathways. Cell 124: 343-354.

Félix M-A, Ashe A, Piffaretti J, Wu G, Nuez I, Bélicard T, Jiang Y, Zhao G, Franz CJ, Goldstein LD, et al. 2011. Natural and experimental infection of Caenorhabditis nematodes by novel viruses related to nodaviruses. PLOS Biol 9: e1000586.

Fischer SEJ, Butler MD, Pan Q, Ruvkun G. 2008. Trans-splicing in C. elegans generates the negative RNAi regulator ERI-6/7. Nature 455: 491-496.

Fischer SEJ, Montgomery TA, Zhang C, Fahlgren N, Breen PC, Hwang A, Sullivan CM, Carrington JC, Ruvkun G. 2011. The 
ERI-6/7 helicase acts at the first stage of an siRNA amplification pathway that targets recent gene duplications. PLOS Genet 7: e1002369.

Fraser AG, Kamath RS, Zipperlen P, Martinez-Campos M, Sohrmann M, Ahringer J. 2000. Functional genomic analysis of C. elegans chromosome I by systematic RNA interference. Nature 408: 325-330.

Friend K, Campbell ZT, Cooke A, Kroll-Conner P, Wickens MP, Kimble J. 2012. A conserved PUF-Ago-eEF1A complex attenuates translation elongation. Nat Struct Mol Biol 19: 176-183.

Gibbings DJ, Ciaudo C, Erhardt M, Voinnet O. 2009. Multivesicular bodies associate with components of miRNA effector complexes and modulate miRNA activity. Nat Cell Biol 11: 1143-1149.

Grishok A, Pasquinelli AE, Conte D, Li N, Parrish S, Ha I, Baillie DL, Fire A, Ruvkun G, Mello CC. 2001. Genes and mechanisms related to RNA interference regulate expression of the small temporal RNAs that control C. elegans developmental timing. Cell 106: 23-34.

Grishok A, Sinskey JL, Sharp PA. 2005. Transcriptional silencing of a transgene by RNAi in the soma of C. elegans. Genes Dev 19: 683-696.

Gu W, Shirayama M, Conte D, Vasale J, Batista PJ, Claycomb JM, Moresco JJ, Youngman EM, Keys J, Stoltz MJ, et al. 2009. Distinct argonaute-mediated 22G-RNA pathways direct genome surveillance in the C. elegans germline. Mol Cell 36: 231-244.

Gu SG, Pak J, Guang S, Maniar JM, Kennedy S, Fire A. 2012. Amplification of siRNA in Caenorhabditis elegans generates a transgenerational sequence-targeted histone $\mathrm{H} 3$ lysine 9 methylation footprint. Nat Genet 44: 157-164.

Guang S, Bochner AF, Pavelec DM, Burkhart KB, Harding S, Lachowiec J, Kennedy S. 2008. An Argonaute transports siRNAs from the cytoplasm to the nucleus. Science 321: 537-541.

Guang S, Bochner AF, Burkhart KB, Burton N, Pavelec DM, Kennedy S. 2010. Small regulatory RNAs inhibit RNA polymerase II during the elongation phase of transcription. Nature 465: 1097-1101.

Han T, Manoharan AP, Harkins TT, Bouffard P, Fitzpatrick C, Chu DS, Thierry-Mieg D, Thierry-Mieg J, Kim JK. 2009. 26G endo-siRNAs regulate spermatogenic and zygotic gene expression in Caenorhabditis elegans. Proc Natl Acad Sci 106: 18674-18679.

Hayes GD, Riedel CG, Ruvkun G. 2011. The Caenorhabditis elegans SOMI-1 zinc finger protein and SWI/SNF promote regulation of development by the mir- 84 microRNA. Genes Dev 25: 2079-2092.

Hibbs MA, Hess DC, Myers CL, Huttenhower C, Li K, Troyanskaya OG. 2007. Exploring the functional landscape of gene expression: Directed search of large microarray compendia. Bioinformatics 23: 2692-2699.

Hsieh J, Liu J, Kostas SA, Chang C, Sternberg PW, Fire A. 1999. The RING finger/B-box factor TAM-1 and a retinoblastomalike protein LIN-35 modulate context-dependent gene silencing in Caenorhabditis elegans. Genes Dev 13: 2958-2970.

Kamath RS, Fraser AG, Dong Y, Poulin G, Durbin R, Gotta M, Kanapin A, Le Bot N, Moreno S, Sohrmann M, et al. 2003. Systematic functional analysis of the Caenorhabditis elegans genome using RNAi. Nature 421: 231-237.

Kelly WG, Fire A. 1998. Chromatin silencing and the maintenance of a functional germline in Caenorhabditis elegans. Development 125: 2451-2456.

Kennedy S, Wang D, Ruvkun G. 2004. A conserved siRNAdegrading RNase negatively regulates RNA interference in C. elegans. Nature 427: 645-649.
Ketting RF, Plasterk RH. 2000. A genetic link between cosuppression and RNA interference in C. elegans. Nature 404: 296-298.

Ketting RF, Fischer SE, Bernstein E, Sijen T, Hannon GJ, Plasterk RH. 2001. Dicer functions in RNA interference and in synthesis of small RNA involved in developmental timing in C. elegans. Genes Dev 15: 2654-2659.

Kim SK, Lund J, Kiraly M, Duke K, Jiang M, Stuart JM, Eizinger A, Wylie BN, Davidson GS. 2001. A gene expression map for Caenorhabditis elegans. Science 293: 2087-2092.

Kim TH, Kim YJ, Cho JW, Shim J. 2011. A novel zinc-carboxypeptidase SURO-1 regulates cuticle formation and body morphogenesis in Caenorhabditis elegans. FEBS Lett 585: 121-127.

Klassen MP, Wu YE, Maeder CI, Nakae I, Cueva JG, Lehrman EK, Tada M, Gengyo-Ando K, Wang GJ, Goodman M, et al. 2010. An Arf-like small G protein, ARL-8, promotes the axonal transport of presynaptic cargoes by suppressing vesicle aggregation. Neuron 66: 710-723.

Knight SW, Bass BL. 2002. The role of RNA editing by ADARs in RNAi. Mol Cell 10: 809-817.

Kudron M, Niu W, Lu Z, Wang G, Gerstein M, Snyder M, Reinke V. 2013. Tissue-specific direct targets of Caenorhabditis elegans $\mathrm{Rb} / \mathrm{E} 2 \mathrm{~F}$ dictate distinct somatic andgermline programs. Genome Biol 14: R5.

Lee YS, Pressman S, Andress AP, Kim K, White JL, Cassidy JJ, Li X, Lubell K, Lim DH, Cho IS, et al. 2009. Silencing by small RNAs is linked to endosomal trafficking. Nat Cell Biol 11: 1150-1156.

Lee H-C, Gu W, Shirayama M, Youngman E, Conte D Jr, Mello CC. 2012. C. elegans piRNAs mediate the genome-wide surveillance of germline transcripts. Cell 150: 1-10.

Linhart C, Halperin Y, Darom A, Kidron S, Broday L, Shamir R. 2012. A novel candidate cis-regulatory motif pair in the promoters of germline and oogenesis genes in C. elegans. Genome Res 22: 76-83.

Lu R, Maduro M, Li F, Li HW, Broitman-Maduro G, Li WX, Ding SW. 2005. Animal virus replication and RNAi-mediated antiviral silencing in Caenorhabditis elegans. Nature 436: 1040-1043.

Lund E, Sheets MD, Imboden SB, Dahlberg JE. 2011. Limiting Ago protein restricts RNAi and microRNA biogenesis during early development in Xenopus laevis. Genes Dev 25: 1121-1131.

Maydan JS, Flibotte S, Edgley ML, Lau J, Selzer RR, Richmond TA, Pofahl NJ, Thomas JH, Moerman DG. 2007. Efficient high-resolution deletion discovery in Caenorhabditis elegans by array comparative genomic hybridization. Genome Res 17: 337-347.

Montgomery TA, Rim Y-S, Zhang C, Dowen RH, Phillips CM, Fischer SEJ, Ruvkun G. 2012. PIWI associated siRNAs and piRNAs specifically require the Caenorhabditis elegans HEN1 ortholog henn-1. PLoS Genet 8: e1002616.

Pavelec DM, Lachowiec J, Duchaine TF, Smith HE, Kennedy S. 2009. Requirement for the ERI/DICER complex in endogenous RNA interference and sperm development in Caenorhabditis elegans. Genetics 183: 1283-1295.

Pushpa K, Kumar GA, Subramaniam K. 2013. PUF-8 and TCER-1 are essential for normal levels of multiple mRNAs in the C. elegans germline. Development 140: 1312-1320.

Robert VJP, Sijen T, van Wolfswinkel J, Plasterk RHA. 2005. Chromatin and RNAi factors protect the C. elegans germline against repetitive sequences. Genes Dev 19: 782-787.

Rocheleau CE, Rönnlund A, Tuck S, Sundaram MV. 2005. Caenorhabditis elegans CNK-1 promotes Raf activation but is not essential for Ras/Raf signaling. Proc Natl Acad Sci 102: 11757-11762. 
Rual J-F, Ceron J, Koreth J, Hao T, Nicot A-S, HirozaneKishikawa T, Vandenhaute J, Orkin SH, Hill DE, van den Heuvel S, et al. 2004. Toward improving Caenorhabditis elegans phenome mapping with an ORFeome-based RNAi library. Genome Res 14: 2162-2168.

Saito K, Ishizu H, Komai M, Kotani H, Kawamura Y, Nishida KM, Siomi H, Siomi MC. 2010. Roles for the Yb body components Armitage and $\mathrm{Yb}$ in primary piRNA biogenesis in Drosophila. Genes Dev 24: 2493-2498.

Saleh M-C, van Rij RP, Hekele A, Gillis A, Foley E, O'Farrell PH, Andino R. 2006. The endocytic pathway mediates cell entry of dsRNA to induce RNAi silencing. Nat Cell Biol 8: 793802.

Schott DH, Cureton DK, Whelan SP, Hunter CP. 2005. An antiviral role for the RNA interference machinery in Caenorhabditis elegans. Proc Natl Acad Sci 102: 18420-18424.

She X, Xu X, Fedotov A, Kelly WG, Maine EM. 2009. Regulation of heterochromatin assembly on unpaired chromosomes during Caenorhabditis elegans meiosis by components of a small RNA-mediated pathway. PLoS Genet 5: e1000624.

Sheth U, Pitt J, Dennis S, Priess JR. 2010. Perinuclear P granules are the principal sites of mRNA export in adult C. elegans germ cells. Development 137: 1305-1314.

Shi Z, Montgomery TA, Qi Y, Ruvkun G. 2013. High-throughput sequencing reveals extraordinary fluidity of miRNA, piRNA, and siRNA pathways in nematodes. Genome Res 23: 497-508.

Sijen T, Fleenor J, Simmer F, Thijssen KL, Parrish S, Timmons L, Plasterk RH, Fire A. 2001. On the role of RNA amplification in dsRNA-triggered gene silencing. Cell 107: 465-476.

Simmer F, Tijsterman M, Parrish S, Koushika SP, Nonet ML, Fire A, Ahringer J, Plasterk RHA. 2002. Loss of the putative RNA-directed RNA polymerase RRF-3 makes C. elegans hypersensitive to RNAi. Curr Biol 12: 1317-1319.

Sleumer MC, Wei G, Wang Y, Chang H, Xu T, Chen R, Zhang MQ. 2012. Regulatory elements of Caenorhabditis elegans ribosomal protein genes. BMC Genomics 13: 433.

Tabara H, Sarkissian M, Kelly WG, Fleenor J, Grishok A, Timmons L, Fire A, Mello CC. 1999. The rde-1 gene, RNA interference, and transposon silencing in C. elegans. Cell 99: 123-132.

Tabara H, Yigit E, Siomi H, Mello CC. 2002. The dsRNA binding protein RDE-4 interacts with RDE-1, DCR-1, and a DExHbox helicase to direct RNAi in C. elegans. Cell 109: 861-871.

Towbin BD, Meister P, Pike BL, Gasser SM. 2010. Repetitive transgenes in C. elegans accumulate heterochromatic marks and are sequestered at the nuclear envelope in a copynumber- and lamin-dependent manner. Cold Spring Harb Symp Quant Biol 75: 555-565.

Updike DL, Strome S. 2009. A genomewide RNAi screen for genes that affect the stability, distribution and function of $\mathrm{P}$ granules in Caenorhabditis elegans. Genetics 183: 1397-1419.

Vasale JJ, Gu W, Thivierge C, Batista PJ, Claycomb JM, Youngman EM, Duchaine TF, Mello CC, Conte D. 2010. Sequential rounds of RNA-dependent RNA transcription drive endogenous small-RNA biogenesis in the ERGO-1/Argonaute pathway. Proc Natl Acad Sci 107: 3582-3587.

Vastenhouw NL, Fischer SEJ, Robert VJP, Thijssen KL, Fraser AG, Kamath RS, Ahringer J, Plasterk RHA. 2003. A genomewide screen identifies 27 genes involved in transposon silencing in C. elegans. Curr Biol 13: 1311-1316.

Wilkins C, Dishongh R, Moore SC, Whitt MA, Chow M, Machaca K. 2005. RNA interference is an antiviral defence mechanism in Caenorhabditis elegans. Nature 436: 1044-1047.

Wu X, Shi Z, Cui M, Han M, Ruvkun G. 2012. Repression of germline RNAi pathways in somatic cells by retinoblastoma pathway chromatin complexes. PLoS Genet 8: e1002542.
Yigit E, Batista PJ, Bei Y, Pang KM, Chen C-CG, Tolia NH, Joshua-Tor L, Mitani S, Simard MJ, Mello CC. 2006. Analysis of the C. elegans Argonaute family reveals that distinct Argonautes act sequentially during RNAi. Cell 127: 747-757.

Zhang C, Montgomery TA, Fischer SEJ, Garcia SMDA, Riedel CG, Fahlgren N, Sullivan CM, Carrington JC, Ruvkun G. 2012. The Caenorhabditis elegans RDE-10/RDE-11 complex regulates RNAi by promoting secondary siRNA amplification. Curr Biol 22: 881-890.

Zheng K, Xiol J, Reuter M, Eckardt S, Leu NA, McLaughlin KJ, Stark A, Sachidanandam R, Pillai RS, Wang PJ. 2010. Mouse MOV10L1 associates with Piwi proteins and is an essential component of the Piwi-interacting RNA (piRNA) pathway. Proc Natl Acad Sci 107: 11841-11846. 


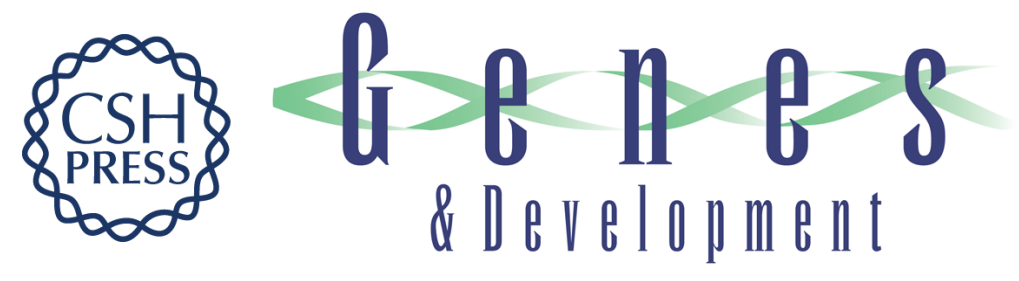

\section{Multiple small RNA pathways regulate the silencing of repeated and foreign genes in C. elegans}

Sylvia E.J. Fischer, Qi Pan, Peter C. Breen, et al.

Genes Dev. 2013, 27:

Access the most recent version at doi:10.1101/gad.233254.113

\section{Supplemental http://genesdev.cshlp.org/content/suppl/2013/12/18/27.24.2678.DC1 Material}

References This article cites 71 articles, 28 of which can be accessed free at: http://genesdev.cshlp.org/content/27/24/2678.full.html\#ref-list-1

Creative This article is distributed exclusively by Cold Spring Harbor Laboratory Press for the first Commons six months after the full-issue publication date (see

License http://genesdev.cshlp.org/site/misc/terms.xhtml). After six months, it is available under a Creative Commons License (Attribution-NonCommercial 3.0 Unported), as described at http://creativecommons.org/licenses/by-nc/3.0/.

Email Alerting Receive free email alerts when new articles cite this article - sign up in the box at the top Service right corner of the article or click here.

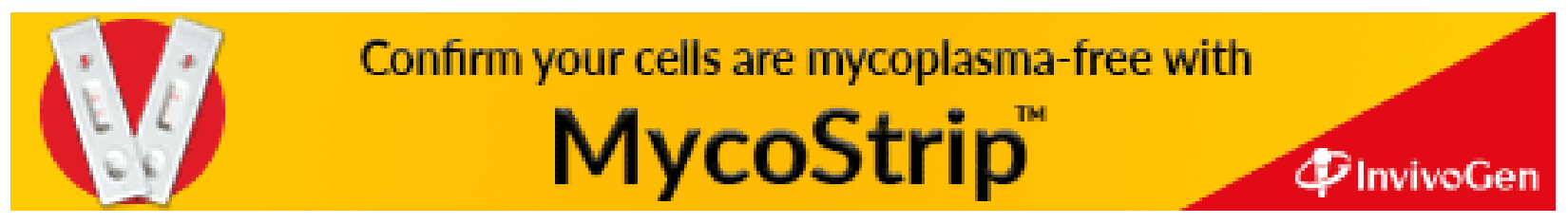

